\title{
UN PRECEDENTE REMOTO DE LA JUDICIAL REVIEW: EL CONTROL JUDICIAL DE LA LEGISLACIÓN DE LAS COLONIAS AMERICANAS
}

\author{
Francisco Fernández Segado \\ fdezsegado@der.ucm.es
}

Recebido em: 27-11-2015

Aprovado em: 26-4-2016

Sumario: I. La arraigada idea de un Fundamental Law en las colonias. II. La existencia de un cierto control judicial de la conformidad de la legislación colonial con las Charters: 1. Las Colonial Charters. Su incipiente consideración judicial como higher law. 2. La Glorious Revolution, la independencia judicial en Inglaterra, la falta de ella en las colonias y el contrapeso del jury trial. 3. El caso Giddings v. Brown (1657). 4. El caso Robin et al. v. Hardaway et al. (1772). III. La revisión de la legislación colonial por el Privy Council y su ocasional aplicación del Ultra Vires Principle: 1. La jurisdicción de apelación del Privy Council. 2. El caso Winthrop v. Lechmere (1727). 3. El caso Philips v. Savage (1737). 4. El caso Camm v. Hansford and Moss (Parson's Cause) (1766).

\section{Resumen:}

Los primeros esbozos de la judicial review en Norteamérica han de situarse en el período colonial. En esa etapa el dictum de Coke en el Bonham's case se iba a convertir en la fuente más importante de la revisión judicial de la legislación. La introducción de la revisión judicial presuponía la idea de la existencia de un Derecho fundamental, esto es, un Derecho superior que los estatutos de las asambleas legislativas coloniales habían de respetar. En el siglo XVIII los colonos iban a encontrar unos sólidos puntos de apoyo para su idea acerca de la existencia de un Derecho fundamental en esas impresionantes construcciones doctrinales de la Ilustración que son los tratados sistemáticos sobre el Derecho natural e internacional. Las

\section{Abstract:}

The first judicial review sketches are found in the colonial period. During this period, Coke's dictum in the Bonham's case became the most important single source of the judicial review notion. The introduction of the judicial review required the idea of a fundamental law, a superior law that colonial laws had to respect. In the 18 th century the colonists would find firm bases for the idea of the existence of a fundamental law in those impressive doctrinal constructions of the Enlightenment, the systematic treaties on natural and international law. The colonial Charters granted by the King were considered by binding courts as legislatures and were applied as a higher law. In the Giddings v. Brown case (1657), for the first time, the Coke's dictum received practical 
Cartas coloniales, otorgadas por el Rey, se consideraron por los tribunales vinculantes respecto a las Legislaturas coloniales, aplicándose como Derecho superior. En el caso Giddings v. Brown (1657) el dictum de Coke recibió por primera vez aplicación práctica al otro lado del Atlántico. En la decisión de este caso el Juez Symonds escribía "que donde una ley es contraria a un Derecho fundamental, es nula".

También el Privy Council, en el ejercicio de su jurisdicción de apelación respecto de los tribunales coloniales, iba a llevar a cabo una revisión judicial de la legislación colonial. Su anulación judicial de los estatutos coloniales se ha equiparado a la revisión judicial de la legislación. De hecho, en el caso Winthrop v. Lechmere (1727), el Privy Council declaró la nulidad de una ley de Connecticut de 1699, la Ley para la solución de las propiedades intestadas, declarándola nula y sin valor a causa de que era "contraria a las leyes de Inglaterra en cuanto que convertía tierras heredadas en distribuibles como propiedades personales y esto no estaba autorizado por la Carta de la Colonia”. En resumen, la etapa colonial, incluso bastante antes de James Otis y del Writs Assistance Case, nos ofrece algunos ejemplos de aplicación de la doctrina de la revisión judicial de la legislación y, sobre todo, nos revela que tal doctrina era muy bien conocida y admitida en amplio sectores del mundo jurídico colonial.

\section{Palabras clave:}

Cartas coloniales, Constitución antigua; Derecho fundamental; Dictum de Coke; Judicial review;Legislación colonial; Privy Council; Tribunales coloniales. application on the other side of the Atlantic. In this case ruling the Judge Symonds wrote that "a law that is repugnant to a fundamental right is void".

Likewise, the Privy Council, in the practice of its appeal's jurisdiction in relation to colonial courts, carried out a judicial review of the colonial legislation. Its judicial annulment of the statutes has been compared to the function of judicial review. In fact, in the Winthrop v. Lechmere case (1727), the Privy Council declared that an Act of Connecticut, the Act for the Settlement of Intestates Estates (1699) was null and void because it was "contrary to the laws of England, in regard it makes lands of inheritance distributables as personal estates, and it is not warranted by the Charter of that Colony". In short, the colonial epoch, even long before of James Otis and the Writs of Assistance Case, offers us some examples of the application of the judicial review of legislation doctrine and, above all, it reveals us that a such doctrine was very well knew and acknowledged in considerable sectors of the legal colonial world.

\section{Key words:}

Ancient constitution; Coke's dictum; Colonial courts; Colonial legislation; Charters; Fundamental law; Judicial review; Privy Council. 


\section{La arraigada idea de un fundamental law en las colonias.}

I. Los primeros esbozos de la judicial review en Norteamérica han de situarse en el período colonial. En esta etapa, la influencia de la doctrina establecida por el Juez Edward Coke, en su célebre dictum del Bonham's Case, interpretado en el sentido de ver en él la doctrina de la judicial review of legislation, será realmente determinante. Como escribiera Corwin ${ }^{1}$, el dictum, tratado al margen de algunas otras de sus ideas, estaba destinado a convertirse en "the most important single source of the notion of judicial review". Baste con recordar que Roscoe Pound, el gran Decano, Decano de Harvard, describió la era colonial como la época de Coke ("the age of Coke")2. Como parece por entero lógico, la introducción de la judicial review iba a presuponer la idea más o menos asentada de la existencia de un fundamental law, esto es, un Derecho superior que los estatutos coloniales debían respetar.

Los primeros colonos eran obviamente ingleses y sus ideas políticas no podían ser sino las imperantes en el siglo XVII en Inglaterra, y entre ellas se hallaba una cierta, imprecisa si se quiere, concepción de la existencia de un fundamental law que debía imponerse a todos los órganos de gobierno. Esa idea de una suerte de superior law a los textos de origen regio o parlamentario había comenzado como una defensa frente a la invasión regia de privilegios muy queridos por sus súbditos, $\mathrm{y}$, ante ello, ya en el siglo XVII comenzó a apelarse a the ancient constitution, que existía desde tiempo inmemorial, y que se convirtió en el argumento político clásico frente a la invasión de derechos llevada a cabo por el rey. "The doctrine of the sovereignty of fundamental law ---escribe Reid³ --- was older than Magna Carta”. Casi todos los ingleses de ambos lados del Atlántico iban a ver en ese fundamental law una guía para la rectitud moral, como también para la constitucionalidad del Derecho ordinario y de la propia acción política. Y así, casi todo el mundo invocaba reiteradamente la Carta Magna, tan ensalzada por Cokie, y objeto de auténtica veneración en las colonias, así como otras leyes fundamentales de la Constitución inglesa. En este marco no ha de extrañar que las Cartas coloniales (colonial Charters) hablaran el lenguaje del fundamental law, garantizando a los colonos los derechos de los ingleses, manteniéndose asimismo por los portavoces

$\left(^{*}\right)$ Catedrático de Derecho Constitucional. Facultad de Derecho. Universidad Complutense de Madrid. Doctor honoris causa por la Università degli Studi di Messina (Italia) y por la Pontificia Universidad Católica del Perú, con sede en Lima. Autor de 35 libros y de más de medio millar de artículos publicados en obras colectivas y revistas científicas de más de una veintena de países de Europa y de América Latina.

$\left.{ }^{* *}\right)$ Artículo inicialmente publicado en el núm. 19 del Anuario lberoamericano de Justicia Constitucional (2015), que edita el Centro de Estudios Políticos y Constitucionales de Madrid.

Edward S. CORWIN, "The < Higher Law> Background of American Constitutional Law" (II), en Harvard Law Review (Harv. L. Rev.), Vol. XLII, 1928-1929, pp. 365 y ss.; en concreto, pp. 379-380.

2 Roscoe POUND, The Formative Era of American Law, Boston (Mass.), 1938, pp. 3 y 6-7. Cit. por Shannon C. STIMSON, The American Revolution in the Law (Anglo-American Jurisprudence before John Marshall), London, The Macmillan Press Ltd., 1990, p. 13.

3 John Phillip REID, Constitutional History of the American Revolution (The Authority to Legislate), Madison (Wisconsin), The University of Wisconsin Press, 1991, p. 6. 
coloniales, como recuerda la doctrina ${ }^{4}$, que tales derechos legales se hallaban igualmente garantizados por un "unwritten law" sin ninguna específica declaración de concesión.

A la vista de lo que se acaba de decir, no es nada de extrañar que la idea de la omnipotencia legislativa acuñada por Blackstone circulara en dirección contraria a las convicciones profundamente arraigadas de los colonos. Berger ${ }^{5}$ ve corroborada esta idea en la propia Declaración de Independencia, en la que puede leerse: "Hemos advertido (a nuestras colegas británicos) de vez en cuando de los intentos de sus legisladores de ampliar una injustificable jurisdicción sobre nosotros". Y es que los colonos creían firmemente en que la naturaleza obligatoria del Derecho se asentaba en "las máximas inmutables de la razón y la justicia”, esto es, en algo diferente de la mera voluntad de la Legislatura.

El concepto tradicional de ese fundamental law ha sido caracterizado por tres componentes: el primero era que se trataba de un Derecho legalmente supremo; el segundo, que era un Derecho no escrito que extraía su contenido de fuentes tales, como los usos y costumbres, o la razón y la justicia; en fin, el tercero, que tal fundamental law era, al menos en ciertas circunstancias, judicialmente exigible. Innecesario es decir que la idea básica subyacente a la judicial review iba a ser la existencia de un fundamental law limitando a la autoridad legislativa.

El contenido de este fundamental law, como fácilmente puede comprenderse, tratándose de un Derecho consuetudinario, era incierto y abierto; en cierto modo, podría decirse del mismo que era inmutable y evolutivo, invariable, pero siempre diferente. Kramer recuerda ${ }^{6}$, que sus exigencias eran considerablemente menos claras que las del common law, que después del siglo XV había quedado centralizado en los royal courts, pasando de esta forma a descansar menos en la costumbre y en la práctica que en el precedente judicial. De lo que no puede caber duda es de la singular posición que los derechos y libertades de la persona iban a gozar en ese fundamental law ${ }^{7}$, que en el fondo era tributaria de una doctrina de natural law que, como señalara Corwin ${ }^{8}$, con diversos corolarios, suministró

\footnotetext{
$4 \quad$ Thomas C. GREY, "Origins of the Unwritten Constitution: Fundamental Law in American Revolutionary Thought", en Stanford Law Review (Stan. L. Rev.), Vol. 30, 1977-1978, pp. 843 y ss.; en concreto, p. 866.

5 Raoul BERGER, Congress v. the Supreme Court, Cambridge (Mass.), Harvard University Press, $2^{\text {nd }}$ edition, 1974 (first published in 1969), p. 30.

$6 \quad$ Larry D. KRAMER, "We the Court" (The Supreme Court 2000 Term. Foreword), en Harvard Law Review (Harv. L. Rev.), Vol. 115, 2001-2002, pp. 5 y ss.; en concreto, p. 19.

$7 \quad$ De la relevancia de estos derechos pueden dar buena idea dos importantes documentos de la etapa colonial. En primer término, la Charter of Liberties and Privileges, aprobada por la primera Asamblea General de Nueva York en 1683, que contenía no sólo el bosquejo de una constitución para la provincia de Nueva York, sino un auténtico Bill of Rights que daba nombre al documento. Aún más elaboradas y explícitas fueron las disposiciones de otro documento, los Rights and Privileges of the Majesty's Subjects, promulgado ocho años más tarde (en 1691) por el mismo órgano colonial. Cfr. al efecto, Bernard BAILYN, The Ideological Origins of the American Revolution, Cambridge (Mass.), The Belknap Press of Harvard University Press, $13^{\text {th }}$ printing, 1976, pp. 193 y ss.

8 Edward S. CORWIN, "The < Higher Law> Background of American Constitutional Law" (II), op. cit., p. 380.
} 
los postulados básicos de la especulación teórica, durante los siglos XVII y XVIII, con un especial impacto sobre el pensamiento político colonial?

II. En el siglo XVIII, los colonos iban a encontrar unos sólidos puntos de apoyo para sus propios puntos de vista sobre la existencia de un fundamental law en esas impresionantes construcciones doctrinales de la Edad de la razón que son los tratados sistemáticos sobre el Derecho natural e internacional. Con la salvedad obvia de Grocio, los autores de estos tratados son mucho menos conocidos hoy, si bien en el XVIII las obras de Vattel, Burlamaqui, Pufendorf e incluso Rutherforth, gozaban de enorme prestigio y ejercieron notable influencia, ayudando a modelar las ideas constitucionales de los colonos. Junto a todos ellos, John Locke, que se convertiría en el auténtico padre ideológico de la Revolución americana. El enorme influjo de su Second Treatise on Government es sobradamente conocido. El Chief Justice Burger ha llegado a hablar ${ }^{10}$ del plagio que Jefferson hizo del mismo en la Declaración de Independencia, aunque tampoco quepa echar en olvido a la Escuela escocesa de la Ilustración (Scottish Enlightenment), una significativa fuente del pensamiento político americano en la época a la que nos estamos refiriendo.

La contribución de estos iuspublicistas fue doble. En primer lugar, insistieron en la importancia del Derecho natural y de los derechos naturales. Locke sería a este respecto el autor paradigmático. Sin embargo, Locke no llegó a reivindicar la fuerza legalmente vinculante de la law of nature, mientras que los restantes sí insistieron en que el poder legislativo no podía legítimamente infringir los principios fundamentales de la moral y de la política, aunque es cierto que ninguno de ellos aludiera de modo expreso a una facultad judicial de revisión de la legislación, ni tampoco de las actuaciones gubernamentales a fin de salvaguardar los derechos individuales que ellos creían que el Derecho natural confería al hombre. En todo caso, estas construcciones doctrinales contribuyeron a revitalizar el natural law, un componente básico de la teoría tradicional inglesa del fundamental law. En segundo término, y esto tendrá una particularísima relevancia, las construcciones dogmáticas de estos autores de la Ilustración, como bien se ha destacado ${ }^{11}$, reforzaron y en parte reformularon la idea de una constitución fija y vinculante que había de establecer limitaciones jurídicas sobre el poder legislativo, que se adicionaban a las impuestas por el Derecho natural.

$\overline{9}$ Cree Rossiter, que en el pensamiento colonial el edificio de la libertad no sólo se apoyaba en el natural law and natural rights, sino también el constitucionalismo Whig y en la virtud, considerándose esta última como una versión terrenal de la law of nature. Un escritor iba a visualizar la virtud del siguiente modo: "in its most general sense, consists in an exact observance of the Laws of Nature", que exige que los ciudadanos contribuyasn tanto como puedan "to the preservation and happiness of mankind in general". Clinton ROSSITER, The First American Revolution (The American Colonies on the Eve of Independence), New York, A Harvest Book, Harcourt, Brace and Company, 1956, pp. 226 y 231.

10 Warren E. BURGER, "The Doctrine of Judicial Review. Mr. Marshall, Mr. Jefferson, and Mr. Marbury", en Current Legal Problems (The Faculty of Laws. University College London), Vol. 25, 1972, pp. 1 y ss.; en concreto, pp. 2-3.

11 Thomas C. GREY, "Origins of the Unwritten Constitution...", op. cit., pp. 860-861. 
La vital importancia que el pensamiento de los referidos autores tendrá para la historia política norteamericana no hace sino corroborar la íntima conexión que en esa época se va a establecer entre la historia política pre-revolucionaria y el pensamiento de la Ilustración europea. Sin embargo, sería una posición excesivamente reduccionista circunscribir la teoría jurídica norteamericana en los tiempos coloniales a la filosofía política de la Ilustración y a los mencionados autores. De ella podría más bien decirse, con Burns ${ }^{12}$, que fue el resultado de una acumulación de ideas que recorre la totalidad de un camino que se inicia con Cicerón y los estoicos, que suministraron la idea de una law of nature y la personificación de la justicia universal, constante y eterna; que sigue con las contribuciones de los medievalistas, como John de Salisbury, según Corwin ${ }^{13}$, "the first systematic writer on politics in the Middle Ages", que contribuyó a caracterizar la doctrina de la autoridad como intrínsecamente condicionada o limitada por su propia naturaleza, al margen ya de que hayamos de recordar que en las páginas de su Policraticus, una sátira de las costumbres de la época, en la que se podía leer lo que sigue: "there are certain precepts of the law which have perpetual necessity, having the force of law among all nations and which absolutely cannot be broken". Salisbury abordará frontalmente los textos del Derecho romano que podían perturbar su teoría, y frente a la bien conocida consideración del príncipe como legibus solutus, el que fuera Obispo de Chartres rechazaría que la voluntad o capricho del príncipe adquiriera sin más la fuerza del Derecho, pudiendo ser legal para él la realización de actos injustos. Salisbury, como puede verse, nos ofrece una prueba patente de que la concepción de un higher law impregna el pensamiento de la Edad Media.

El camino que recorrerá la teoría jurídica americana colonial encontrará otro punto de referencia de la mayor relevancia en Henry de Bracton, Juez del King's Bench durante el reinadso de Enrique III, el primogénito de Juan sin Tierra, que reinaría en Inglaterra entre 1216 y 1272. Bracton coleccionó unas dos mil decisiones judiciales que publicó a continuación en De Legibus et Consuetudinibus Angliae, poniendo por primera vez el naciente common law en contacto directo con las ideas medievales continentales de un higher law. Célebre es el siguiente pasaje de su obra:

\footnotetext{
"The King himself ought not to be subject to man, but subject to God and to the law, for the law makes the King. Let the King then attribute to the law what the law attributes to him, namely, dominion and power, for there is no King where the will and not the law has dominion" ${ }^{14}$.
}

12 Edward M. BURNS, "Madison's Theory of Judicial Review", en Kentucky Law Journal (Ky. L. J.), Vol. XXIV, 1935-1936, pp. 412 y ss.; en concreto, pp. 412-413.

13 Edward S. CORWIN, "The <Higher Law> Background of American Constitutional Law" (I), en Harvard Law Review (Harv. L. Rev.), Vol. XLII, 1928-1929, pp. 149 y ss.; en concreto,. p. 164.

$14 \quad$ Apud Edward S. CORWIN, en Ibidem, p. 172. 
Estas palabras, que parcialmente repetirá Coke ante el Rey Jacobo I, vuelven a mostrarnos la característica idea medieval de que toda autoridad deriva del Derecho, y como tal se halla limitada por ese mismo Derecho.

Recordemos finalmente, aun cuando sin detenernos en ello, la especial relevancia que tuvo el pensamiento Whig (en el que se alinearán figuras tan distantes como el conservador John Dickinson o el radical Samuel Adams), defensor de esa noción de un fundamental law tras el que subyacía una idea de libertad. No podemos olvidar la trascendental figura de Thomas Paine, cuyos textos tendrán un gran influjo en la conformación de los sentimientos generales de la comunidad. Piénsese, por ejemplo, en su obra Common Sense, de la que se imprimirían miles de copias, distribuidas a lo largo y ancho de todas las colonias. Su célebre afirmación de que "in America the law is king" 15 , que ha sido parafraseada, como "in America, constitutional law, rather that man, is king" "16, hizo necesario un cambio en la teoría en cuanto a la localización de la soberanía. La autoridad absoluta del Parlamento en cuanto verdadero soberano se transferiría ahora al pueblo. La Revolución americana dejó esa situación meridianamente clara: el pueblo, como auténtico soberano, asumió todo su protagonismo. Como en uno de los artículos más influyentes de la doctrina constitucional se escribió: "The Revolution came, and what happened then? Simply this: we cut the cord that tied us to Great Britain, and there was no longer an external sovereign. Our conception now was that <the people> took his place; that is to say, our own home population in the several States were now their own sovereign" ${ }^{17}$. Pocos años después, el pueblo, no sus representantes, se convertía en "the highest lawmaking body", y el celebérrimo, "We the People of the United States, in order to form a more perfect Union...”, c on el que se abre la Constitución de 1787, no haría sino dar testimonio de ello, todo lo cual, por cierto, tendría como resultado final una redefinición de los jueces como agentes del pueblo soberano, iguales de algún modo en autoridad a los legisladores, lo que en la Constitución se traduciría en el ascenso del judiciary a la posición de un departamento de gobierno semejante a los otros dos.

\footnotetext{
15 El párrafo completo en que se formula la celebérima afirmación está redactado en los siguientes términos:

"But where, say some, is the King of America? I'll tell you, friend, he reigns above, and doth not make havoc of mankind like the Royal Brute of Great Britain. Yet that we may not appear to be defective even in earthly honours, let a day be solemnly set apart for proclaiming the Charter; let it be brought forth placed on the Divine Law, the Word of God; let a crown be placed thereon, by which the world may know, that so far as we approve of monarchy, that in America the law is king. For as in absolute governments the King is law, so in free countries the law ought to be king; and there ought to be no other. But lest any ill use should afterwards arise, let the Crown at the conclusion of the ceremony be demolished, and scattered among the people whose right it is". Apud The Writings of Thomas Paine, collected and edited by Moncure Daniel CONWAY, New York, Burt Franklin, reprinted, 1969, Vol. I (1774-1779), p. 99. (Common Sense, en pp. 67-120).

16 Robin WEST, "Tom Paine's Constitution", en Virginia Law Review (Va. L. Rev.), Vol. 89, 2003, pp. 1413 y SS.; en concreto, p. 1414.

17 James B. THAYER, "The Origin and Scope of the American Doctrine of Constitutional Law", en Harvard Law Review (Harv. L. Rev.), Vol. VII, 1893-1894, pp. 129 y ss.; en concreto, p. 131.
} 
En definitiva, el fundamental law ha venido a ser algo así como el plasma sanguíneo que ha vivificado ese cuerpo siempre en movimiento, desde los mismos comienzos de su existencia, que ha sido el pensamiento jurídico americano. Y en ello ha de verse la razón de ser última de la progresiva y cada vez más acentuada sensibilidad existente, ya en la época colonial, hacia la judicial review. Podría añadirse, que incluso en Inglaterra, el progresivo arraigo durante el siglo XVIII de la doctrina de la soberanía legislativa no fue capaz de expulsar la noción de un fundamental law. Tanto Locke como Bolingbroke aludieron a un Derecho fundamental, y el propio Blackstone, paradigma de la defensa de la soberanía legislativa en sus célebres Commentaries on the Laws of England, estaba de acuerdo en que el Parlamento se hallaba limitado por lo que él denominó "an overriding natural law"18.

\section{La existencia de un cierto control judicial de la conformidad de la legislación colonial con las Charters.}

\section{Las colonial Charters. Su incipiente consideración judicial como higher law.}

El modelo de gobierno de cada colonia inglesa en los territorios de América del Norte iba a venir determinado por lo que bien podría denominarse su "constitución", empleando ciertamente el término en un sentido impropio. Los principales elementos de tal "constitución" iban a ser: la Charter, las concesiones o patentes regias y sus correspondientes renovaciones, los encargos e instrucciones al gobernador, las llamadas orders-in-council y cualesquiera otras instrucciones provenientes de Inglaterra, como también las costumbres y prácticas locales. En la experiencia jurídica de las colonias previa a la Independencia iban a tener un particular protagonismo las Charters, otorgadas y garantizadas por el propio rey ${ }^{19}$.

Las primeras Charters fueron las de Virginia y Nueva Inglaterra, otorgadas por el Rey Jaime I en 1606 y 1620, y por el Rey Carlos I en 1629, que se iban a contemplar como delegaciones incompletas de la autoridad política. La Carta de Massachusetts fue anulada en 1684, pasando siete años después este territorio a considerarse como una esfera de la Corona. La Carta de gobierno de Rhode Island y de las Plantaciones de Providence, otorgada por Carlos I en 1643, y ampliada por Carlos II en 1663, al igual que la de Connecticut, otorgada en 1662, fueron modeladas con base en el gobierno de una ciudad inglesa. De esta forma, los gobiernos previstos por las Charters eran corporaciones civiles de naturaleza marcadamente municipal. La diversidad de estos gobiernos coloniales dio paso en 1660 a la aparición de una política de administración colonial que pronto condujo a la uniformidad

\footnotetext{
18 Gordon S. WOOD, "The Origins of Judicial Review", en SuffolkUniversity Law Review (Suffolk U. L. Rev.), (Suffolk University Law School, Boston), Vol. XXII, 1988, pp. 1293 y ss.; en concreto, p. 1297.

19 Clinton ROSSITER, The First American Revolution, op. cit., p. 101.
} 
de derechos políticos y jurídicos en los diferentes territorios coloniales. Y así, por una royal commission de $1^{\circ}$ de diciembre de 1660 , se creó un Consejo permanente (standing council) de 48 nobles y caballeros nombrados por la Corona a los que se encargó de los asuntos relacionados con las plantaciones. En 1674 las funciones de este Consejo se transfirieron al King's Privy Council.

En 1696, la Cámara de Comercio y de las Plantaciones (Board of Trade and Plantations) se hizo cargo finalmente de todo lo relativo a las plantaciones americanas, nombre genérico con el que se identificaban los territorios allende el Atlántico. Las actuaciones de este cuerpo administrativo emanaban de la Corona, atribuyéndose el conocimiento de las apelaciones que contra las mismas pudieran formalizar las colonias al Privy Council. En fin, quizá convenga añadir, que en todos los gobiernos coloniales hubo una limitación uniforme del poder legislativo. Como recuerda Fowler ${ }^{20}$," no laws were to be enacted except such as were not contrary to the laws of England. The legislative power was thus both a delegated and a restricted one".

Las Charters otorgadas por el Rey fueron consideradas por los tribunales como vinculantes respecto a las Legislaturas coloniales, aplicadas por ellos mismos, no sin algunos bruscos vaivenes, como higher law. Alguna Carta fue incluso más allá. Y así, la Carta de Carolina, de 1665, al otorgar a los propietarios el poder de hacer las leyes con el consentimiento de la Asamblea, imponía la restricción de que "the said laws be consonant to reason, and as near as may be conveniently, agreeable to the laws and customs of this our realm of England". Sería justamente la misma limitación existente sobre la legislatura colonial de Connecticut, la que el Privy Council hizo respetar treinta y cuatro años más tarde.

Las colonial Charters utilizaron el lenguaje propio de un fundamental law, garantizando a los colonos los derechos de los ingleses; por poner un ejemplo, la Carta de la Massachusetts Bay Colony garantizaba a todos los colonos "all liberties and immunities of free and natural subjects.... as if they and everie of them were borne within the realm of England". Las Cartas de Virginia, Connecticut, Rhode Island, Maryland, Carolina y Georgia acogían previsiones similares. Pero por si existiese alguna duda, recuerda $\mathrm{Grey}^{21}$, que los oradores de la época colonial se refirieron habitualmente en sus discursos a que estos derechos legales se hallaban igualmente garantizados a los colonos por un unwritten law, sin necesidad de que existiera una específica concesión al respecto.

Esta superioridad de las Cartas sobre las normas legislativas coloniales (pues la gran masa de normas legislativas que incidían sobre la vida colonial no provenía del Parlamento británico sino de las propias legislaturas coloniales) determinó que, en algunos casos, las

\footnotetext{
$20 \quad$ Robert Ludlow FOWLER, "The Origin of the Supreme Judicial Power in the Federal Constitution", en American Law Review (Am. L. Rev.), Vol. 29, 1895, pp. 711 y ss.; en concreto, pp. 715-718.

21 Thomas C. GREY, "Origins of the Unwritten Constitution...", op. cit., p. 866.
} 
últimas fueran declaradas nulas al entrar en conflicto con las primeras, justamente de modo análogo a lo que sucedía si la ordenanza municipal de una ciudad, o la reglamentación de una corporación excedían de los poderes delegados a la ciudad o a la corporación, supuesto en el que habían de considerarse nulas al haber sido tales normas ultra vires, siguiéndose en último término la pauta fijada por los propios tribunales de la metrópoli. Ello era bien significativo si se piensa que, como bien se ha escrito, "the juristic basis of judicial review is the doctrine of ultra vires" 22 . Prueba fehaciente de que esta facultad judicial fue reconocida la encontramos en un documento oficial de Sir William Thomson, Procurador General (Solicitor General) de Gran Bretaña, que el 5 de abril de 1718 expresaba que un estatuto de Carolina, que imponía una alta tasa sobre las mercancías, no era acorde con la razón ("consonant to reason") y "by no means agreeable to the laws of Britain"23. Con todo, no se puede ignorar que esta revisión de la legislación colonial por los tribunales de las colonias fue muy episódica ${ }^{24}$.

Conviene no olvidar, por lo demás, que las numerosas limitaciones que recaían sobre la legislación colonial circunscribían esta a la mera administración, aproximándola a una simple actuación administrativa. Esto se tradujo en que los colonos se acostumbraron paulatinamente a contemplar las legislaturas coloniales como órganos dotados de una autoridad limitada, enormemente alejadas del poder absoluto de que se revestiría, tras la Glorious Revolution, el Parlamento británico. Los colonos llegaron a comprender muy bien que algunas leyes no eran Derecho, y este sistema prevaleció por todas partes durante varias generaciones, circunstancia que daría pie a un sector de la doctrina para pensar ${ }^{25}$, que una doctrina así de arraigada no parecía probable que, de modo repentino, se apagara y desapareciera de la superficie, simplemente por el hecho de que las colonias se independizaran de Inglaterra.

Pero es asimismó evidente que la doctrina de la judicial review, íntimamente conexa con la idea de un fundamental law, sólo iba a poder llegar a ser un principio de Derecho positivo, después de alcanzada la Independencia, una vez adoptadas unas Constituciones escritas que contenían limitaciones vinculantes que quedaban al margen del poder gubernamental. Por lo mismo, la judicial review no llegó a ser una parte del Derecho viviente ("a part of the living law”) hasta la década anterior a la adopción de la Constitución federal, poco más o menos. En esa época, diversos casos litigiosos planteados en diferentes Estados,

\footnotetext{
22 Mark ELLIOTT, The Constitutional Foundations of Judicial Review, Oxford/Portland (Oregon), Hart Publishing, 2001, p. 23.

23 Dudley Odell McGOVNEY, "The British Origin of Judicial Review of Legislation", en University of Pennsylvania Law Review (U. Pa. L. Rev.), Vol. 93, 1944-1945, pp. 1 y ss.; en concreto, p. 9.

$24 \quad$ Sosin, un tanto exageradamente, ha llegado a escribir que esta revisión por los tribunales coloniales "was almost unknown". J. M. SOSIN, The Aristocracy of the Long Robe (The Origins of Judicial Review in America), New York/Westport, Connecticut/London, Greenwood Press, 1989, p. 146.

25 William M. MEIGS, "The American Doctrine of Judicial Power, and Its Early Origin", en American Law Review (Am. L. Rev.), Vol. 47, 1913, pp. 683 y ss.; en concreto, p. 689.
} 
con Constituciones ya vigentes, vinieron a entrañar reivindicaciones directas de la judicial review. Es en sintonía con esta idea, por lo que el propio Chief Justice John Marshall podía afirmar en la Marbury opinion ${ }^{26}$, no tanto que la Constitución establece la judicial review, cuanto que la misma "confirms and stregthens the principle" 27.

\section{La Glorious Revolution, la independencia judicial en Inglaterra, la falta de ella en las colonias y el contrapreso del jury trial.}

El escaso apreció que en una etapa ya avanzada de la época colonial iban a tener los colonos hacia su judiciary no dejó de ser un obstáculo, no insuperable, desde luego, para que arraigara en esta época la judicial review, y no sólo eso, sino incluso para su fortalecimiento tras la Independencia. Tal circunstancia iba a ser la resultante de que durante gran parte de esta época los jueces fueron vistos, como dice Harrigton ${ }^{28}$, como meros apéndices del ejecutivo ("mere appendages of the executive"), más aún, como una multitud de "pencos políticos" ("a crowd of political hacks"). La mayor parte de los observadores políticos de la época fueron propensos a contemplar el judiciary como una herramienta puesta en manos del ejecutivo; si se tiene presente el oprobio que se atribuyó a los gobernadores reales, se puede entender que el mismo sentimiento se proyectara hacia sus nombramientos judiciales. Y ello no deja de sorprender a la vista del trascendental impacto que sobre la independencia judicial tuvo en Inglaterra la Glorious Revolution. Vale la pena, y séanos permitido este excursus, recordar lo acontecido en Inglaterra y confrontarlo con la situación colonial.

Hablar del principio de la independencia judicial en Inglaterra exige de inmediato aludir a la Revolución Gloriosa. En efecto, la Glorious Revolution iba a hacer de la independencia del judiciary el eje del gobierno constitucional británico. Con anterioridad a la llegada de Guillermo III, Rey de Inglaterra entre 1689 y 1702, esposo de María, hija de Jacobo II, y primer monarca que subió al trono tras la Revolución, la prerrogativa real había sido utilizada por los Estuardo no sólo para cambiar las leyes, sino también para suspender o sustituir a los jueces. En su espléndida historia de la primera revolución moderna, Pincus recuerda ${ }^{29}$, que ya en el reinado de Carlos II se comenzó a nombrar a los jueces en función de la voluntad del rey más que según su buen comportamiento. Esta innovación vino a implicar que tanto Carlos como Jacobo se iban a atrever a destituir a aquellos jueces de los

\footnotetext{
$26 \quad$ La sentencia puede verse, entre otras obras, en Marbury versus Madison. Documents and Commentary, Mark A, GRABER and Michael PERHAC (editors), Washington, CQ Press (A Division of Congressional Quarterly Inc.), 2002, pp. 191-219.

27 Bernard SCHWARTZ, A History of the Supreme Court, New York/Oxford, Oxford University Press, 1993, p. 42.

28 Matthew P. HARRINGTON, "Judicial Review Before John Marshall", en George Washington Law Review (Geo. Wash. L. Rev.), Vol. 72, 2003-2004, pp. 51 y ss.; en concreto, p. 63.

29 Steve PINCUS, 1688. La primera revolución moderna, Barcelona, Acantilado, 2013, pp. 270-271.
} 
tribunales de common law cuyas opiniones se hallaran en conflicto con sus reales pareceres. Carlos destituyó a doce jueces por razones políticas en un cuarto de siglo; Jacobo iba a acelerar enormemente esa tendencia, y en menos de cuatro ańos depuso a otros doce jueces por la misma razón.

El Act of Settlement de 1701, en lo que vino a constituir una de las señas de identidad británica,estableció que el nombramiento de los jueces se mantendría mientras mantuvieran un buen comportamiento (quamdiu se bene geserint), no pudiendo ser removidos del cargo sino por expresa petición de las dos Cámaras del Parlamento. Al aceptar la independencia judicial, bien puede decirse que los Reyes Guillermo y María se convirtieron en los primeros monarcas constitucionales.

Esta visión de la independencia judicial no iba sin embargo a pasar a las colonias del otro lado del Atlántico. No obstante la lucha de los colonos por conseguir análoga independencia para sus órganos judiciales, Jorge III (Rey entre 1760 y 1820) mantuvo el cargo judicial dependiente de su exclusiva voluntad, como había acontecido en Inglaterra hasta el año 1701, sosteniendo un argumento tan fútil, y sobre todo tan irreal, como el de que el estado de conocimiento jurídico en las colonias eran tan bajo que resultaba difícil poder encontrar hombres competentes para decidir los casos judiciales ${ }^{30}$. No ha de extrañar que fuera ésta una de las cuestiones incluidas en el listado de quejas expuestas frente al Rey en la Declaración de Independencia. "Ha hecho ---se puede leer en ella---los jueces dependientes tan sólo de su voluntad para el ejercicio de sus cargos y la cantidad y pago de sus salarios" 31 .

La preocupación ante el peligro de manipulación judicial por unos jueces, carentes de una verdadera independencia, puede comprenderse aún mejor si se tiene presente la más que notable discreción judicial existente entre los jueces de las colonias, lo que era la resultante de la pluralidad de fuentes del Derecho de los colonos (inglesas unas, coloniales las otras). En 1768, el Gobernador de Nueva York lamentaba que "las cuestiones de una causa dependían no tanto del derecho de un cliente como del aliento del juez ("the breath of the Judge"), y lo que se consideraba un excelente alegato en un circuito, era rechazado en otro $^{32}$. La consecuencia de todo ello era tanto la flexibilidad como la inseguridad, y, por encima de todo, un extraordinario grado de discreción judicial. Y aunque ciertamente no se hubiera olvidado la máxima que en su Essay on Judicature sentara el gran filósofo y jurista

\footnotetext{
Archibald COX, "The Independence of the Judiciary. History and Purposes", en University of Dayton

31 A esta queja se añadia otra en relación a la Administración de justicia: "He (el Rey) has obstructed the Administration of Justice, by refusing his Assent to Laws for establishing Judiciary Powers". El texto de la Declaración de Independencia puede verse en la obra From the Declaration of Independence to the Constitution (The Roots of American Constitutionalism), edited with an introduction, by Carl J. FRIEDRICH and Robert G. McCLOSKEY, Indianapolis (Indiana)/New York, The Bobbs-Merrill Company Inc., 1954, pp. 3 y ss.

32 Gordon S. WOOD, "The Origins of Judicial Review", en Suffolk University Law Review (Suffolk U. L. Rev.), (Suffolk University Law School, Boston), Vol. XXII, 1988, pp. 1293 y ss.; en concreto, p. 1300.
} 
Francis Bacon (1561-1626), quien fuera Abogado de la Corona en los primeros años del siglo XVII, "Judges ought to remember that their office is jus dicere and not to make or give law", la realidad era que los jueces habían de discernir a través del Derecho lo que era justo y, a través de ello, el deber de los jueces de conservar la ley y no de cambiarla se relativizaba en ocasiones notablemente.

En este contexto se puede entender que, contrariamente a la práctica inglesa del common law, otorgando a los jueces la determinación exclusiva sobre las cuestiones de Derecho, en las colonias, los jurados iban a ocupar el lugar verdaderamente central de los tribunales, pues a ellos se encomendó decidir no sólo sobre las cuestiones relativas a los hechos, sino también sobre la aplicación del Derecho, tanto en casos civiles como criminales. Aunque los jueces coloniales solían ser personalidades locales relevantes, lo cierto es que su único rol iba a ser el de guiar, no el de decidir, pues salvo en algunas acciones de equidad, estrictamente limitadas, e incluso inexistentes en algunas de las colonias, ellos no podían dictar un veredicto sin el previo pronunciamiento del jurado. Las declaraciones de tres de los más eminentes abogados americanos de fines del siglo XVIII, John Adams, Thomas Jefferson y John Jay, apoyan esta tesis. En una fecha tan tardía como es la del año 1793, John Jay, ocupando la Chief Justiceship de la United States Supreme Court, informaba a un jurado en un a caso civil, de que tenía derecho a encargarse por sí mismo de decidir el Derecho a aplicar, al igual que dilucidar los hechos en controversia. Ambos objetos, concluía Jay, son legítimos dentro del poder decisorio del jurado ${ }^{33}$.

Se entiende así a la perfección la trascendencia que tuvo en esta época la protección del derecho al jury trial, que se mantendría tras la Independencia, y que revela la importancia que los colonos atribuyeron a prácticas y costumbres inveterados que limitaban las facultades del legislativo. Jefferson visualizaría el trial by jury como la única ancla ("the only anchor") imaginada por los hombres a través de la cual un gobierno podía ser retenido dentro de los principios de la constitución, describiendo después el jurado (the jury) como una inestimable institución que contenía a los jueces y representaba al pueblo en la rama judicial ("curbed judges and represented the people in the judicial branch") ${ }^{34}$.

Por otro lado, la facultad de declarar la ley por los jurados ("the law-finding power of the juries") sugiere de modo ineluctable que los miembros del jurado llegaban al tribunal con preconcepciones compartidas acerca de la sustancia del Derecho a aplicar. La cuestión llegó a plantearse con el paso de los años. En 1788, en el caso Pettis v. Warren, desencadenado por una demanda planteada por un negro esclavo para su libertad ante un tribunal de Connecticut, se recusó a un jurado por tener una opinión preconcebida, la de que "no negro, by the laws of this state, could be holden a slave". El tribunal de

\footnotetext{
W3 William E. NELSON, "Marbury v. Madison, Democracy, and the Rule of Law", en Tennessee Law Review (Tenn. L. Rev.), Vol. 71, 2003-2004, pp. 217 y ss.; en concreto, p. 221.

34 Apud Shannon C. STIMSON, The American Revolution in the Law, op. cit., p. 87.
} 
primera instancia (trial court) anuló la recusación del jurado por tal causa, y la Connecticut Supreme Court confirmó esa decisión al considerar que "an opinion formed and declared upon a general principle of law, does not disqualify a juror to sit in a cause in which that principle applies" 35 .

En los tribunales americanos de nuestros días, los jueces dan a los jurados instrucciones sobre el Derecho, y si un jurado deja de seguirlas, su veredicto, con la única salvedad de un veredicto de absolución de un demandado acusado de un delito, será rechazado. En frontal contraste con ello, los jueces americanos del siglo XVIII, con frecuencia, no daban a los jurados instrucciones claras. A veces incluso, las instrucciones eran contradictorias, y en la mayoría de los casos no dejaban de ser breves y rudimentarias. Como recuerda Nelson ${ }^{36}$, casi todos los tribunales del XVIII americano actuaban con más de un juez en los estrados, y parece haber sido una regla general para cada juez integrante del tribunal, el haber pronunciado un discurso ("a charge") al jurado, no obstante la falta de sintonía existente en ocasiones entre unos y otros jueces. Pero incluso ante instrucciones meridianamente claras y armónicas por parte de los jueces, los jurados podían entender el Derecho como consideraran conveniente. John Adams, uno de los más relevantes abogados de la época pre-revolucionaria, siempre sostuvo, que aunque los jurados decidieran el Derecho en una dirección contraria a la que se les había dado por los jueces, eran sus veredictos los que decidían el Derecho aplicable, porque no era sólo un derecho del jurado, sino también un deber, "to find the verdict according to his own best understanding, judgment and conscience though in direct opposition to the direction of the court" ${ }^{37}$.

Las circunstancias expuestas no iban a impedir que la judicial review fuera recepcionándose de modo progresivo en las colonias. Bien al contrario, en la parte final del amplio tracto histórico al que nos estamos refiriendo, encontramos diferentes ejemplos que confirman que los líderes coloniales intentaron recurrir al mecanismo de la revisión judicial para hacer frente a los principios dimanantes de la soberanía parlamentaria. El encasillamiento de la reivindicación de la judicial review en el contexto de la lucha política entre el Parlamento británico y los colonos ha llevado a algún autor ${ }^{38}$ a pedir cautela a la hora de enjuiciar estas reivindicaciones, si bien, a nuestro entender, el contexto en el que puedan enmarcarse no es razón suficiente para privarle de su valor, al margen ya de que encontremos manifestaciones de la judicial review que no se vinculan con ese enfrentamiento político al que acabamos de aludir. La exposición que sigue creemos que contribuye a confirmarlo.

\footnotetext{
$35 \quad$ Apud William E. NELSON, "Marbury v. Madison and the Establishment of Judicial Autonomy", en Journal of Supreme Court History (J. Sup. Ct. Hist.), Vol. 27, Issue 3, 2002, pp. 240 y ss.; en concreto, p. 243.

$36 \quad$ William E. NELSON, "Marbury v. Madison, Democracy...", op. cit., p. 220.

37 Apud Shannon C. STIMSON, The American Revolution in the Law..., op. cit., pp. 55-56.

38 Matthew P. HARRINGTON, "Judicial Review Before John Marshall", op. cit., p. 64.
} 


\section{El caso Giddings v. Brown (1657).}

I. La perceptible influencia en las colonias de la doctrina sentada por el Juez Edward Coke en el Bonham's case puede apreciarse perfectamente en Massachusetts, en el caso Giddings v. Brown (Browne, según algunos) (1657), en el que, como reconoce la doctrina con carácter generalizado, el dictum del Bonham's case recibió aplicación práctica por primera vez al otro lado del Atlántico. Un autor tan relevante en la materia como es el caso de Corwin, considera esta decisión del mayor interés, y ello no sólo por ser la más temprana pista ("the earliest hint") de la judicial review en América, sino por proporcionar asimismo la primera declaración del proverbio que puede contemplarse como el origen popular ("the folk-origin"), por así decirlo, del Derecho constitucional americano: "que la propiedad de A no puede darse a B sin su consentimiento" ${ }^{39}$. También Plucknett considera al respecto que, en Giddings $v$. Browne, "we have the first clear example of an act of legislature being invalidated by the judiciary in America" ${ }^{40}$. Muy similar es la apreciación de Smith, para quien este caso entraña "the very first clear holding by which a judicial body in the Americas ruled a legislative act, by a town meeting, invalid because of the dicta in the Bonham 's case" ${ }^{41}$, mientras que Grey considera ${ }^{42}$, que "the tradition of a judicially enforceable higher law of $<$ common right and reason> (the tradition of Dr. Bonham's Case) has been implemented during the early colonial period in Giddings v. Browne".

Es bien conocido, y se admite por toda la doctrina americana, que el pensamiento jurídico de Coke iba a tener un notabilísimo impacto en las colonias, un impacto que, aunque tendemos a centrarlo en la doctrina de la judicial review, desbordó con creces ese ámbito. Por lo que a su célebre dictum se refiere, era fácilmente accesible al aparecer recogido en los Abridgments, verdaderas enciclopedias del Derecho inglés, muy manejados y estudiados por los abogados de las colonias. El dictum de Coke se repitió en los Abridgments de Viner, Bacon y Comyns, y además de ello, como escribe Goebel ${ }^{43}$, Coke llegó a ocupar un lugar un lugar preeminente en el "stock" usado por los abogados en los common law cases. En definitiva, parece admitido por un amplio sector de la doctrina, que un siglo antes del Writs of Assistance Case (1761) ${ }^{44}$, el dictum del Juez Coke iba a ser aplicado en

\footnotetext{
$39 \quad$ Edward S. CORWIN, "The Establishment of Judicial Review" (I), en Michigan Law Review (Mich. L. Rev.), Vol. IX, 1910-1911, pp. 102 y ss.; en concreto, p. 105.

40 Theodore F. T. PLUCKNETT, "Bonham's Case and Judicial Review", en Harvard Law Review (Harv. L. Rev.), Vol. XL, 1926-1927, , pp. 30 y ss.; en concreto, p. 62.

$41 \quad$ George P. SMITH, II0, "Dr. Bonham's Case and the Modern Significance of Lord Coke's Influence", en University of Washington Law Review (U. Wash. L. Rev.), Vol. 41, 1966, pp. 297 y ss.; en concreto, p. 314.

42 Thomas C. GREY, "Origins of the Unwritten Constitution...", op. cit., p. 848.

43 Julius GOEBEL, Jr., "Ex Parte Clio", (Books Review), en Columbia Law Review (Colum. L. Rev.), Vol. LIV, 1954, pp. 450 y ss.; en concreto, p. 455.

44 Sobre este caso, cfr. Francisco FERNÁNDEZ SEGADO, "James Otis y el Writs of Assistance Case (1761)", en Anuario Iberoamericano de Justicia Constitucional (AlbJC), núm. 18, 2014, pp. 155 y ss.
} 
el caso que estamos examinando. Y en cuanto a su significado, en la América colonial, fue inequívoco. El pensamiento germinal que Coke expresara en 1610 había evolucionado y se había convertido en la doctrina de que un tribunal podía considerar nulo un texto legal promulgado por una asamblea legislativa limitada por un fundamental law, cuando el tribunal considerara que la ley había transgredido sus límites. Hechas estas consideraciones previas, hemos de centrarnos ya en el caso en cuestión.

II. Los hechos desencadenantes del caso son bien sencillos. Ipswich, un pueblo de la colonia de Massachusetts, aprobó a través de su asamblea legislativa local, proporcionar una vivienda para el Sr. Cobbet, ministro evangelista, y con tal finalidad a la vista impuso un impuesto a pagar por los ciudadanos. El litigio surgió cuando el Sr. Giddings y otros se negaron a pagar la tasa municipal, ante lo que Brown, el oficial municipal de justicia, ordenó a los funcionarios municipales que se apropiaran de mercancías propiedad del Sr. Giddings para hacer de esta forma efectivo el pago. Giddings demandó entonces a Brown por daños.

Del caso iba a conocer el Juez Symonds, de Boston, que más tarde llegó a ser Vicegobernador (Deputy Governor) de la colonia. Symonds había nacido en Inglaterra en 1595, descendiendo de un a honorable familia de Essex. En 1637 llegó a Ipswich (Massachusetts Bay Colony), convirtiéndose con el paso del tiempo en un admirador y seguidor del common law inglés, que iba a tener muy presente en su sentencia. El Juez Symonds falló en favor del demandante, Sr. Giddings, considerando que el caso versaba sobre:

"(A) fundamental law (....) such a law as that God and nature have given to a people (....). It is against a fundamental law in nature to be compelled to pay that which others doe give (....). Let us not (here in New England) despise the rules of the learned in the lawes of England, who have great helps and long experience. I First rule is, that where a law is (...) repugnant to fundamental law, it's voyd; as if it gives power to take away an estate from one man and give it to another" ${ }^{35}$.

El Juez Symonds iba a apoyar su decisión con determinados pasajes extraídos de un libro de Sir Henry Finch publicado en 1627 (su First Book of Law), aunque su primera edición fuera de 1613, en el que podía leerse, que el common law no era otra cosa sino common reason, y que las leyes positivas contrarias al mismo eran nulas, al igual que las contrarias a la law of nature ("laws positive which are directly contrary to the former ---the law of nature and of reason--- lose their force, and are no laws at all") ${ }^{46}$.

Más allá del Giddings case, la doctrina se ha hecho eco asimismo de diversas manifestaciones que, mediado el siglo XVII, apuntan a la aparición en Massachusetts de 
un renovado interés por el common law, al considerarlo como la más sólida garantía de los derechos de los colonos, y en conexión con el mismo, una cierta tendencia hacia el estudio de las obras de Edward Coke. Es bien significativo al respecto, que en 1647 la General Court de Massachusetts ordene que le sean llevados dos ejemplares de varias de las obras de Coke, sus Reports, Coke upon Littleton, Coke upon Magna Carta... ${ }^{47}$. Otro indicio al que se puede atender es que en 1688, con ocasión de la abrogación de su Charter por Jacobo II, los bostonianos iban a reivindicar claramente la independencia, en apoyo de la cual, según se recoge en un Account of the Colony and Provinces of New England in general, se hablaba de "to hold forth a law book \& quote the authority of the Lord Coke to justifie their setting up for themselves".

Un hecho muy poco conocido, y del que existen escasos datos, es que en 1688 Maryland aprobaba una ley para incentivar la fabricación de productos textiles; de conformidad con la misma, los productos locales recibían subsidios que debían ser recaudados a su vez de acuerdo con un reparto impositivo llevado a cabo por los comisionados designados por los tribunales del condado. Algunos plantadores del "Somerset County" adujeron que la ley no podía ponerse en vigor, y ante ello el tribunal del condado de Somerset decidió que la ley en cuestión era nula, habiéndose de pensar que por argumentos muy semejantes a los esgrimidos por el Juez Symonds.

III. Otro episodio descubierto por los historiadores del Derecho en la provincia de Carolina del Sur, que proporciona una clara evidencia del ejercicio por un tribunal colonial de la facultad judicial de considerar un estatuto inconstitucional (esto es, contrario al fundamental law) nulo, tiene lugar en 1724. Se trata del caso Dymes v. Ness, poco conocido hasta que McGovney, siguiendo a Wallace, un historiador de Carolina del Sur, se hizo eco de él ${ }^{48}$, si bien quedó constancia del mismo en los diarios de la Commons House, la Cámara baja de la Legislatura de Carolina del Sur.

El 22 de diciembre de 1726 se planteaba y votaba afirmativamente en la mencionada Commons House la siguiente cuestión:

\footnotetext{
"that the opinion of the Generall Court in Charles Town of the $22^{\text {nd }}$ of August One thousand Seven hundred \& twenty four was contrary \& repugnant to a clause in an Act of the Generall Assembly of this Province".
}

El 18 de enero siguiente, Thomas Hepworth, Chief Justice de la General Court, frecuentemente llamada Supreme Court de la Provincia, se levantó de su lugar como miembro de la Commons House y declaró que estaba en cama enfermo cuando se suscitó

\footnotetext{
$\overline{47}$ Theodore F. T. PLUCKNETT, en Ibidem, pp. 61-62.

48 Cfr. al efecto, Dudley Odell McGOVNEY, "The British Origin of Judicial...", op. cit., pp. 10-11.
} 
y votó la mencionada cuestión, requiriendo ser oído para justificar el procedimiento de la General Court que había sido cuestionado por la Cámara. Aunque sus argumentos no quedaron reflejados en las actas, algunas intervenciones y documentos ulteriores pueden ilustrar acerca de los mismos. Particular interés presenta un informe del Comité de agravios de la Cámara que fue aprobado por ésta y en el que se puede leer lo que sigue:

\footnotetext{
"Your Committee.... Report they have rec'd \& read the Representation of the Charles Town Judges wherein as they conceive is contained some things which we believe the Judges themselves scarce understand $\&$ therefore no reflection on the Committee if they are at a loss to guess at their meaning $\&$ allso several Positions of a dangerous Tendency to this Province, as first the whole Government is arraigned for passing Laws as 'tis suggested contrary to the Kings Instructions \& Repugnant to the Laws of England. Secondly the Judges Suggest they have a power of dispensing with all such Laws at pleasure $\&$ that they are Sole Judges \& Interpreters of our Laws which your Committee are of opinion is assuming a power Superior to that of this house $\&$ equal with that of the whole Legislative body united".
}

La prueba de que la General Court había dictado una decisión judicial en la que debió considerar una ley de la Legislatura nula con fundamentos constitucionales parece bastante clara. Y en todo caso, a la vista del texto transcrito, una cosa parece incontrovertible: la General Court había considerado que un estatuto inconstitucional era nulo. La única duda es la de si, más allá de ese pronunciamiento, el tribunal dictó efectivamente una sentencia en esa misma dirección.

\section{El caso Robin et al. v. Hardaway et al. (1772).}

I. Otro caso, aunque ciertamente bastante posterior al caso de Giddings, es el que iba a tener lugar en Virginia, en 1772, Robin et al. v. Hardaway et al. El litigio se suscitó cuando varias personas de descendencia india intentaron reivindicar su libertad a pesar de que una ley de la Asamblea de Virginia de 1682 (entre otras normas legales) les reducía a la esclavitud. George Mason, un influyente abogado virginiano, actuando en representación de los indios, sostuvo que la ley virginiana de 1682, que otorgaba a los comerciantes de esclavos ("slave traders") el derecho de vender a los descendientes de nativos americanos violaba los derechos naturales de tales nativos, y por lo mismo el fundamento filosófico de los derechos individuales en la teoría política liberal, y justamente por ello esa ley debía considerarse nula. Vale la pena recordar algunas de las consideraciones de Mason: 


\begin{abstract}
"All acts of legislature apparently contrary to natural right and justice are, in our laws, and must be in the nature of the things, considered as void. The laws of nature are the laws of God, whose authority can be superseded by no power on earth. A legislature must not obstruct our obedience to Him from Whose punishments they cannot protect us. All human constitutions which contradict His laws, we are in conscience bound to disobey. Such have been the adjudications of our courts of justice" ${ }^{49}$. (Todos los actos de la legislatura evidentemente contrarios a los derechos naturales y a la justicia son, de conformidad con nuestras leyes, y deben ser por la propia naturaleza de las cosas, considerados nulos. Las leyes de la naturaleza son las leyes de Dios, cuya autoridad no puede ser reemplazada por ningún poder sobre la tierra. Una legislatura no debe obstruir nuestra obediencia a Él, de cuyo castigo no puede protegernos. Estamos obligados en conciencia a desobedecer todas las constituciones humanas que contradigan Sus leyes. Tales han sido las decisiones de nuestros tribunales de justicia).
\end{abstract}

Y a modo de verificación de esa tradición judicial a la que aludía Mason, éste mencionaba expresamente el Bonham's Case y el Calvin's Case, así como los Reports del Chief Justice Hobart, en los que éste confirmaba el dictum de Coke. Es de interés hacernos eco de esa referencia de Mason a "the adjudications of our courts of justice", con la que no sólo quería significar que el tribunal de Virginia era parte del sistema judicial británico, sino que con ella estaba dando a entender la generalizada admisión en este sistema judicial del dictum de Coke.

El abogado de la parte contraria también pronunció un discurso erudito, apelando a Pufendorf como prueba de que la esclavitud formaba parte de la law of nature, contraponiendo al dictum de Coke las reflexiones antagónicas de los Commentaires de Blackstone.

Los jueces del caso hubieron de esforzarse para evitar pronunciarse sobre la legitimidad de la ley en cuestión. Y así, en una maniobra que reflejaba que todavía en esa época, muy próxima ya al inicio de la Revolución, el dogma británico de la supremacía legislativa encontraba cierto arraigo en el mundo jurídico colonial, el tribunal resolvió el litigio soslayando un pronunciamiento de fondo, al considerar que la odiosa ley había quedado abrogada en 1705. En cualquier caso, el razonamiento de este destacado abogado virginiano revelaba, al menos, la creciente predisposición entre los miembros de los Colegios de Abogados de impugnar ante los tribunales aquellos textos normativos que entendían contrarios a ese fundamental law que creían que debía ser tutelado y priorizado en sede judicial.

II. También en el año 1772 algunos abogados de Maryland, en oposición a una ley promulgada siete décadas antes para establecer la Iglesia de Inglaterra, que facultaba al clero para exigir un impuesto en metálico, reclamaron ante los tribunales de la provincia

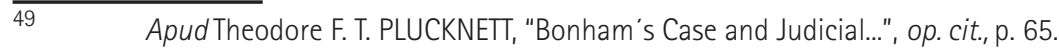


que inaplicaran el texto legal o que lo declararan nulo al hallarse en conflicto con un higher law. Dos casos, ambos identificados como Lord Proprietor v. John Chapman, se suscitaron ante la Provincial Court de Maryland, planteándose la mencionada cuestión. Y aunque la Corte evitó el tema, instando al jurado a que abordase tan sólo los hechos de los casos, lo cierto es que en junio de 1773 la House of Delegates, Cámara baja de la Legislatura de Maryland, resolvió que la ley promulgada en 1702 "was not enacted by legal and constitutional authority and is therefore void"50.

Aunque también podría aportarse algún testimonio en contrario $^{51}$, los ejemplos comentados muestran que el dictum de Coke no sólo no era desconocido ni ignorado en el mundo jurídico colonial, sino que, lejos de ello, fue arraigando y fermentando de modo progresivo. "Long before Americans drafted their constitutions ---ha escrito Hamburger ${ }^{52}$--judicial review developed in the context of assumptions about the hierarchy of law and the duty of judges to decide in accord with law. Consequently, in the 1770s, American judges were already familiar with what today is called judicial review”. Innecesario es decir que la posición mantenida por James Otis en el celebérrimo Writs of Assistance Case no hace sino corroborar aún más cumplidamente esta apreciación.

\section{La revisión de la legislación colonial por el Privy Council y su ocasional aplicación del ultra vires principle.}

\section{La jurisdicción de apelación del Privy Council.}

I. El control de la monarquía británica sobre la administración de justicia colonial en los siglos XVII y XVIII se visualiza en la concentración de la jurisdicción de apelación respecto de los tribunales coloniales en el Privy Council ("the King in Council"). La jurisdicción de apelación ante el "King in Council" vino a asegurar importantes ventajas tanto para la Corona como para los colonos. Para éstos, representó un medio de desagravio frente a los procedimientos un tanto arbitrarios de los tribunales coloniales, que en ocasiones se veían afectados por prejuicios locales que pesaban más que las consideraciones de Derecho y de justicia. Adicionalmente, algunos estatutos coloniales se iban a encontrar

Apud J. M. SOSIN, The Aristocracy of the Long Robe..., op. cit., p. 147.

51 El Chief Justice Michie, de Carolina del Sur, en el caso Williams v. Executors (1759-1760), al discutirse la cuestión de si los tribunales coloniales gozaban de esta facultad de revisión judicial, negó que dispusieran de la misma, considerando que tales tribunales se hallaban subordinados y sólo "the King in Council" podia considerar los actos legislativos ultra vires. Loren P. BETH, "The Judicial Committee of the Privy Council and the Development of Judicial Review", en The American Journal of Comparative Law (Am. J. Comp. L.), Vol. 24, 1976, pp. 22 y ss.; en concreto, pp. 41-42.

52 Philip HAMBURGER, "Law and Judicial Duty", en George Washington Law Review (Geo. Wash. L. Rev.), Vol. 72, 2003-2004, pp. 1 y ss.; en concreto, p. 9.
} 
en contradicción con derechos sustantivos o procesales de los individuos; así, por ejemplo, los acerbos enfrentamientos políticos que sacudieron la colonia de Nueva York, a inicios del siglo XVIII, condujeron a la aprobación de normas completamente arbitrarias ${ }^{53}$. Para la Corona, este control a través de la apelación proporcionaba un medio de impedir cambios importantes en el Derecho colonial sin el consentimiento de la madre patria. A juicio de Schlesinger ${ }^{54}$, autor de un estudio clásico sobre el tema, el Privy Councilvino a sostener una relación con los tribunales coloniales análoga a la que la Supreme Court mantiene con los tribunales estatales en el actual sistema constitucional norteamericano.

La verificación de la conformidad de los estatutos coloniales con un standard constitucional, por así llamarlo, viniera éste dado por una charter, una ley del Parlamento, el common law o incluso una carta municipal, como reconoce la doctrina ${ }^{55}$, iba desde luego a facilitar el camino hacia la judicial review, por cuanto los colonos se familiarizaban desde bien jóvenes con la idea de que las asambleas legislativas coloniales disponían de unos poderes limitados por la existencia de unas normas superiores que la autoridad legislativa venía obligada a respetar. Más aún, se ha llegado a considerar ${ }^{56}$, que el más obvio, si es que no el más significativo, legado del Privy Council appeals system, tal y como operó en las colonias americanas, fué su influencia sobre la adopción de la judicial review. Y es que no puede caber duda de que la aplicación ocasional por el Privy Council del ultra vires principle supuso la anulación de actos legislativos coloniales, por un órgano, en lo que ahora interesa, judicial, lo que no entrañaba otra cosa más que un ejercicio de revisión judicial ${ }^{57}$. Como bien se ha escrito, "the power to disallow colonial laws and the power of judicial review appeared the same in both intent and consequence" 58 .

II. Hemos de comenzar precisando que el órgano que básicamente va a ocupar nuestra atención, el Privy Council, no sólo iba a llevar a cabo una revisión judicial de la legislación colonial, sino también un control administrativo de la misma, por extraño que

$53 \quad$ En diciembre de 1702, una Order in Council anuló un estatuto de Nueva York declarando fuera de la ley a Philip French y a Thomas Wenham al inventar un mecanismo para su condena, el de dejar de aparecer a requerimiento de la autoridad dentro de un período de diez días, algo que el Privy Council consideró contrario al Derecho inglés, que permitía un tiempo mucho mayor en casos semejantes. De elloo se hace eco J. M. SOSIN, en The Aristocracy of the Long Robe, op. cit., p. 144.

$54 \quad$ Arthur Meier SCHLESINGER, "Colonial Appeals to the Privy Council" (I), en Political Science Quarterly (Pol. Sci. Q.), Vol. 28, No. 2, June, 1913, pp. 279 y ss.; en concreto, p. 279.

55 Joseph H. SMITH, "Administrative Control of the Courts of the American Plantations", en Columbia Law Review (Colum. L. Rev.), Vol. LXI, 1961, pp. 1210 y ss.; en concreto, p. 1253.

$56 \quad$ Loren P. BETH, "The Judicial Committee of the Privy Council...", op. cit., p. 40.

57 En sentido análogo, entre otros, David P. CURRIE, "The Constitution in the Supreme Court. The Powers of the Federal Courts, 1801-1835", en The University of Chicago Press (U. Chi. L. Rev.), Vol. 49, 1982, pp. 646 y ss.; en concreto, p. 655.

58 P. Allan DIONISOPOULOS and Paul PETERSON, "Rediscovering the American Origins of Judicial Review: A Rebuttal to the Views Stated by Currie and Other Scholars", en John Marshall Law Review (J. Marshall L. Rev.), Vol. 18, 1984-1985, pp. 49 y ss.; en concreto, p. 55. 
ello pueda parecer. A este respecto, Goebel ha deslindado con toda nitidez lo que identifica como un "judicial control of colony legislation" de lo que considera un "administrative control of colony legislation" 59 . El control administrativo iba a hacerse recaer sobre un Comité del Privy Council, el Lords Committee of Trade and Plantations, al que se confió conocer de los asuntos relacionados con las plantaciones hacia 1675. Innecesario es decir, que es el control judicial el que presenta verdadero interés para el objeto de este trabajo.

Recuerda Haines ${ }^{60}$, que ninguna revisión sistemática de la legislación colonial se estableció hasta 1660. En marzo de 1675, como se acaba de decir, todos los asuntos relacionados con las colonias se hicieron revertir a la Comisión de veintiún consejeros anteriormente citada, conocida generalmente como los Lords of Trade. La preocupación por las amenazas sobre el comercio marítimo, que como es evidente se acentuaban en tiempo de guerra, condujo a Guillermo III a disolver la mencionada Comisión y a crear una Comisión ejecutiva para el comercio y las plantaciones, comúnmente conocida como el Board of Trade. Las leyes se transmitían por los gobernadores coloniales al principal Secretario de Estado, y después al Privy Council, que oía con carácter previo un dictamen de los "Commissioners of Trade". Sería a partir del año 1696, cuando se operativizó de modo efectivo este mecanismo de control. Ese año el Parlamento británico formuló una declaración acerca de la supremacía de sus normas sobre los estatutos coloniales, considerando que cualquier estatuto colonial "anywise repugnant" respecto de las leyes de la navegación ("Navigation Acts") "or to any other law hereafter" hecha por el Parlamento y aplicable a la colonia sería "illegal, null and void"61. La primera regulación general de esta cuestión por la Corona ya había tenido lugar por medio de la Order in Council de 23 de enero de 1684, en la que se estableció que no se admitiría ninguna apelación de las colonias "without sufficient security.... to prosecute their appeals effectually and to stand the award of his Majestry in council thereupon"62.

Lo que se acaba de seńalar ya nos muestra, y es importante tenerlo presente, que junto a la función de revisión judicial el Privy Counciliba a llevar a cabo otras funciones de control de la legislación colonial que no respondían en absoluto a los parámetros propios de lo que hoy conocemos como judicial review. Y ello no sólo porque el canon de constitucionalidad, por así considerarlo, por supuesto impropiamente, no venía dado por un fundamental law, sino porque, más allá de ello, las normas coloniales no se iban a sujetar tan sólo a un control de constitucionalidad, si se le quiere llamar así, sino que iban asimismo a ser enjuiciadas

\footnotetext{
Cfr. al respecto, Julius GOEBEL, Jr., Antecedents and Beginnings to 1801 (History of the Supreme Court of the United States. Vol. 1), New York/London, The Oliver Wendell Holmes Devise, Macmillan Publishing Co., Inc./ Collier Macmillan Publishers, $2^{\text {nd }}$ printing, 1974, pp. 60-83.

60 Charles Grove HAINES, The American Doctrine of Judicial Supremacy, Berkeley, California, University of California, $2^{\text {nd }}$ edition, 1932, p. 45.

61 Dudley Odell McGOVNEY, "The British Privy Council's Power to Restrain the Legislatures of Colonial America: Power to Disallow Statutes: Power to Veto", en University of Pennsylvania Law Review (U. Pa. L. Rev.), Vol. 94, 1945-1946, pp. 59 y ss.; en concreto, p. 59.

$62 \quad$ Apud Arthur Meier SCHLESINGER, "Colonial Appeals..." (I), op. cit., p. 280.
} 
desde la óptica de su conveniencia y oportunidad políticas, al margen ya, además, de que no se iba a seguir ningún procedimiento jurisdiccional. Como escribe Frank ${ }^{63}$, el aspecto más significativo de la revisión por el Privy Council de los problemas jurídicos coloniales iba a ser el de que, por virtud de su doble jurisdicción, en él se fundían un sistema de revisión judicial y otro de revisión legislativa, lo que le facultaba para desaprobar una ley colonial mediante una suerte de veto y para anular un estatuto colonial en el curso de la decisión de un caso litigioso, al hilo de su rol de último órgano judicial de apelación frente a las decisiones de los tribunales coloniales.

En realidad, el Privy Council disponía de tres tipos de facultades para impedir la entrada en vigor de una ley colonial o, en su caso, para anularla. La primera de ellas era el rechazo ("disallowance") o revocación ("repeal") de los estatutos coloniales ${ }^{64}$. La segunda facultad era el veto de tales estatutos. La última, la anulación judicial (“judicial annulment”) de los estatutos, esto es, la que se equipara con la judicial review of legislation. Aunque es la última facultad la que para nosotros presenta interés, cabe recordar que la primera, como antes se dijo, se vino aplicando a partir de los años 1660, siendo activamente utilizada a lo largo de todo el período colonial, mientras que el veto no se aplicó propiamente a los estatutos coloniales, identificándose como tal más bien la decisión de un gobernador colonial de, siguiendo las instrucciones del gobierno británico, instar a la legislatura a que se insertara en el texto del estatuto una cláusula suspendiendo su entrada en vigor hasta tanto el texto recibiera la "king's approbation", lo que venía a operar como una suerte de veto suspensivo, y de hecho significaba la aprobación del Privy Council. El rechazo de la aprobación real equivalía obviamente a un veto absoluto. En definitiva, en la función fiscalizadora de la legislación colonial llevada a cabo por el Privy Council convivían varios procedimientos de control diferentes, uno de ellos, desde luego, reconducible a la judicial review.

Podría pensarse, y así lo han hecho algunos autores, que con ese control judicial llevado a cabo en virtud de su naturaleza de última instancia judicial de apelación, el Privy Council, de modo parejo a como pudieron hacer algunos tribunales coloniales, estaba dando vida a la judicial review, pero tal idea no dejaría de ser un tanto simplista e incluso carente de rigor, por cuanto esta revisión de las leyes coloniales por su posible violación de los principios que se anudaban a la razón, del common law o, más ampliamente, del propio Derecho inglés, e incluso de las Charters, lo único que revelaba era su coherencia con una práctica familiar en Inglaterra, que se remontaba muy allá en el tiempo, en realidad a la Edad Media (aunque las circunstancias histórico-constitucionales impidieran finalmente

\footnotetext{
63 John P. FRANK, "Historical Bases of the Federal Judicial System", en Indiana Law Journal (Ind. L. J.), Vol. 23, 1947-1948, pp. 236 y ss.; en concreto, pp. 239-240.

$64 \quad$ En algunos casos, los estatutos fueron rechazados largo tiempo después de haber sido promulgados. Así, un estatuto de Carolina del Sur para "encourage the settlement of South Carolina", promulgado en 1696, fue rechazado 38 años después. En otros casos, leyes que habian estado en vigor durante una generación fueron después rechazadas. Dudley Odell McGOVNEY, "The British Privy Council's Power to Restrain the Legislatures...", op. cit., p. 72
} 
el moderno arraigo de esa práctica), procedente de la revisión judicial de diversos actos domésticos, incluyendo los actos de la Corona y de las corporaciones. Como escribiera Hamburger ${ }^{65}$, ni en Inglaterra ni en sus colonias era una novedad la judicial review.

La diferenciación entre el control administrativo y el control judicial de la legislación colonial explica muy bien las diferencias en el cómputo de los casos de control de la legislación colonial por el Privy Council que encontramos entre la doctrina. Así, mientras Haines, en su clásico libro, facilita unos datos cuantitativos que pueden parecer absolutamente desmesurados, Schlesinger proporciona datos harto diferentes. La razón de las enormes diferencias en el cómputo es sencilla: mientras el primero se está refiriendo al control administrativo, el segundo está contemplando el procedimiento que podemos reconducir a la judicial review. Schlesinger contabiliza un total de 265 casos de revisión de estatutos a lo largo de un siglo ${ }^{66}$. Frente a ello, Haines estima (para una época semejante, aunque algo más breve) que el Privy Council revisó nada menos que 8.563 leyes aprobadas por las trece asambleas coloniales en el período que media entre 1696 y 1776, 80 años pues, lo que supone un promedio anual de más de un centenar de leyes fiscalizadas a través de esos dos procedimientos administrativos a los que aludimos con anterioridad. De ese elevadísimo número de leyes sometidas a control, un total de 469 (un 5'5 por 100) fueron rechazadas mediante Orders in Council ${ }^{67}$. Si se atiende a los rasgos que caracterizaron el control a que se refiere Haines, no debe extrañar que esta revisión de la legislación colonial por el Privy Council se haya considerado por algún autor como próxima al veto ejecutivo norteamericano ${ }^{68}$, aunque también es cierto que el término "veto" se reservó específicamente a uno de los tres mecanismos de que disponía el Privy Council para impedir la entrada en vigor de la legislación colonial. En definitiva, el control administrativo predominó, de lejos, sobre el control judicial, pero ello no debe conducirnos, ni mucho menos a excluir que el Privy Council ejerciera, en algunos casos al menos, un a auténtica facultad de revisión judicial, más o menos acorde con los parámetros actuales. Más aún, Schlesinger ha considerado que, al menos en tres de los casos de que conoció el Privy Council en el ejercicio de su función de revisión judicial de la legislación, este órgano anuló leyes de las legislaturas coloniales ${ }^{69}$.

\footnotetext{
65 Philip HAMBURGER, "Law and Judicial Duty", op. cit., p. 17. "The review of legislation ---añade Hamburger más adelante (Ibidem, p. 20)--- had been familiar from medieval theory and in a more practical way from the review of the legislative acts of subordinate bodies, such as corporations and colonies".

$66 \quad$ Entre 1680 y 1780, el más significativo periodo de aplicación del appellate system, según Schlesinger, 265 casos llegaron al Privy Council procedentes de las colonias continentales de Inglaterra, lo que significaba cinco apelaciones bianuales. El mayor número de casos, 78 en total, provino de Rhode Island, siguiéndole Virginia con 53 casos y Massachusetts con 44. A lo largo del siglo XVIII hubo un perceptible incremento en el número de casos, constatado año tras año, aunque el autor lo desvincula del crecimiento de la población. Arthur Meier SCHLESINGER, "Colonial Appeals to the Privy Council" (II), en Political Science Quarterly (Pol. Sci. Q.), Vol. 28 , No. 3, September, 1913, pp. 433 y ss.; en concreto, pp. 446-447.

67 Charles Grove HAINES, The American Doctrine of Judicial Supremacy, op. cit., p. 49.

68 Benjamin F. WRIGHT, The Growth of American Constitutional Law, Chicago \& London, Phoenix Books, University of Chicago Press, reprinted, 1967 (first edition in 1942), p. 13.

69 Arthur Meier SCHLESINGER, "Colonial Appeals..." (I), op. cit., p. 279.
} 
Las apelaciones iban a venir delimitadas frente a tres tipos de normas: 1) regulaciones de los gobiernos locales; 2) cartas coloniales y concesiones de la Corona, y 3) leyes aprobadas por las legislaturas coloniales. Antes de que se cerrara el siglo XVII, se planteó la cuestión de si los casos concernientes a una infracción de las leyes de comercio ("Acts of Trade") podían ser apelados ante el King in Council. El 27 de mayo de 1697, el propio Privy Council emitió una Order admitiendo las apelaciones de funcionarios de aduanas a la Corona en casos de incautaciones por comercio ilegal. Este tipo de casos supuso una amplia proporción respecto del total de casos objeto de apelación.

Cualquier litigante insatisfecho ante la decisión de un tribunal colonial podía solicitar de ese mismo tribunal una apelación ante el King in Council. Si el permiso para la apelación se le otorgaba, el litigante quedaba en libertad para proseguir su apelación ante el Privy Council. Si tal permiso le era denegado por el tribunal colonial, podía dirigirse directamente al Privy Council instándole a que su apelación fuera admitida y vista. El Privy Council, tras una consulta con el Committee of Appeals, decidía lo que considerara oportuno, aun cuando lo habitual era que se concediera la apelación solicitada. En algunas ocasiones, esto se hizo incluso respecto de casos en que el período de un año previsto para apelar ya había finiquitado. Una apelación podía ser también provisionalmente admitida "if the Governor and Council there have no other legal objection thereto"70.

Los legisladores coloniales, como regla general, no dieron muestras de oposición a este sistema de apelaciones, pero de este hecho no cree Schlesinger que deba deducirse que no hubiera oposición en las colonias al mismo, aunque ya señalamos que tal sistema no dejaba de encerrar sus ventajas para los colonos. En cualquier caso, hubo intentos de impedir su aplicación, e incluso, en el caso específico de Massachusetts, llegó a aprobarse una legislación obstructiva, que en el fondo respondía a la sistemática reivindicación que Massachusetts mantuvo siempre de su independencia judicial ${ }^{71}$.

\section{El caso Winthrop v. Lechmere (1727).}

I. El primero de los grandes casos que llegó al Privy Council en relación a la validez de una ley colonial iba a ser el caso Winthrop v. Lechmere (1727). Los hechos del caso no son nada complicados. En noviembre de 1692, Massachusetts aprobó una ley para la asignación y distribución de las propiedades de los intestados (“intestates”), esto es, de quienes fallecían

\footnotetext{
$70 \quad$ Arthur Meier SCHLESINGER, "Colonial Appeals..." (II), op. cit., p. 437.

71 En noviembre de 1637, la Massachusetts General Court rechazaba una solicitud de apelación al Reverendo John Wheelwright, declarando al respecto que: "an appeal did not lie in this case, for the King having given us authority by his grant under the great seal of England to hear and determine all causes without reservation, we are not to admit any such appeal... and if an appeal should lie in one case, it might be challenged in all, and then there would be no use of government amongst us". Apud Arthur Meier SCHLESINGER, "Colonial Appeals..." (I), op. cit., pp. 292-293.
} 
sin haber expresado su voluntad testamentariamente. En 1699, Connecticut aprobó una ley semejante, de conformidad con la cual los bienes raíces de un intestado eran divididos de modo igual entre los hijos, con la sola salvedad de que al mayor se le había de dar una doble porción de la tierra, sujeta en su caso al interés de la dote de la viuda mientras ésta viviera, salvo que, como ocurrió en el caso que nos ocupa, la misma se perdiera de resultas de un matrimonio ulterior de la viuda. La ley satisfacía con ello una costumbre prevalente desde sus primeros tiempos en Nueva Inglaterra, aunque opuesta a lo que se preveía por el common law, de acuerdo con el cual, el hijo mayor era el único heredero y tenía derecho a la totalidad de los bienes raíces, sin tener en cuenta a los restantes hijos.

En 1717, el General Waite Winthrop, de Boston, hijo del fundador y primer Gobernador de Connecticut, John Winthrop, que llegó a su vez a ser Chief Justice de la Superior Court of Judicature de Massachusetts, donde pasó los últimos años de su vida, murió intestado, dejando dos hijos, John Winthrop y Ann, la mujer de Thomas Lechmere, un comerciante de Boston, quien será la persona demandada en la apelación formalizada ante el Privy Council. El difunto tenía grandes propiedades de tierras en Connecticut, cuya administración recayó, en febrero de 1717, sobre su hijo John, tras una primera decisión judicial de la llamada Court of Probates (tribunal de legalización de los testamentos) de Connecticut. Su hermana Ann y su cuñado Lechmere lograron que la Legislatura de Connecticut les concediera un nuevo juicio ante la misma Court of Probates, que en esta ocasión forzó la partición de la tierra entre los dos hermanos, revocando la administración inicialmente concedida al mayor. Con base en que, de conformidad con el common law, él era el único heredero, y en que la ley de Connecticut era nula por su contradicción con el common law, John Winthrop apeló a la Superior Court de Connecticut, que no obstante esos argumentos, el 22 de marzo de 1725 confirmó la segunda decisión judicial, manteniendo la administración del tercio de la propiedad de las tierras dejadas a su muerte por el General Waite Winthrop en manos de Ann Winthrop y de su marido Thomas Lechmere.

Así las cosas, John solicitó de la Superior Court que se le autorizara apelar ante el King in Council, aduciendo al respecto que:

\footnotetext{
"he was in a contemptuous manner denyed him, tho' often demanded and insisted on; the Court saying that they were not under your Majestie's government, and their Charter knew nothing of your Majesty in Council, and that he might come and tell your Majesty that they denyed him an appeal"72.
}

No obstante sus acres observaciones, la Superior Court denegó la solicitud reclamada, tras lo que John Winthrop presentó un memorial ante la Asamblea General de Connecticut,

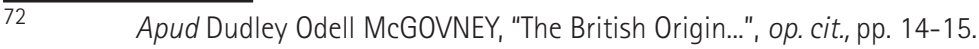


expresando su deseo de apelar, petición también desestimada por la Asamblea, tras lo que John Winthrop se dirigió directamente al Privy Council, aduciendo que la ley de Connecticut era nula en cuanto contraria al common law de Inglaterra y a la Colonial Charter de la propia provincia. En febrero de 1726, una Order in Council otorgó "an appeale to his Majesty in Council, from the said two sentences past in the Superior Court of Connecticut". Admitida pues la apelación, en diciembre de 1726 el caso fue enjuiciado ante el Committee for Appeals.

El Attorney General, Philip Yorke, y el Solicitor General, Charles Talbot, dos futuros Lords Chancellor, que asumieron la defensa de John Winthrop ante el Privy Council, coincidieron en que aunque por los términos en que se hallaba redactada la Charter de Connecticut, la Legislatura de la provincia disponía de la facultad de elaborar y aprobar leyes relativas a la propiedad, tales normas legales debían acomodarse a los requisitos de que fueran razonables y no contradijeran las leyes de Inglaterra. Y tras ello concluían: "To repeal or to disallow a law was one thing; to declare a law of no effect ab initio, from the outset, was another"73. El rol de Philip Yorke parece que tuvo especial trascendencia. Este gran jurista inglés (que fue sucesivamente Solicitor General, entre 1720 y 1724 , Attorney General, entre 1724 y 1733, Chief Justice, de 1733 a 1737, y Lord Chancellor, entre 1737 y 1756) estaba avalando con su posición la doctrina de la anulación judicial de la legislación, que de esta forma bien puede decirse que no podía contar con un patrocinador de mayor relevancia.

El 15 de febrero de $1727^{74}$, se hacía pública la sentencia, en la que se declaraba la nulidad de la ley de Connecticut ("the said Act for the Settlement of Intestates Estates should be declared null and void"), a causa de que la ley era "contrary to the laws of England, in regard it makes lands of inheritance distributable as personal estates, and is not warranted by the Charter of that Colony", revocando de esta forma las decisiones judiciales de los tribunales de Connecticut y otorgando la totalidad de las propiedades a John Winthrop. La sentencia concluía de la siguiente manera:

\footnotetext{
"His Majesty, taking the same into his royal consideration, is pleased with the advice of his Privy Council to approve of the said report, and confirm the same in every particular part thereof, and pursuant thereunto to declare that the aforementioned act entituled An Act for the Settlement of Intestate Estates is null and void, and the same is hereby accordingly declared to be null and void and of no force or effect whatever. And his Majesty is hereby further pleased to order"75.
}

\footnotetext{
73 Apud J. M. SOSIN, The Aristocracy of the Long Robe ..., op. cit., p. 146.

74 Esta fecha es la que ofrece McGovney, pues Schlesinger da otra diferente, la de 13 de febrero de 1728, en su artículo, "Colonial Appeals..." (II), op. cit., p. 441.

75 Apud Dudley Odell McGOVNEY, "The British Origin...", op. cit., p. 16.
} 
Contemplada desde la perspectiva de la larga y sólida tradición inglesa de anulación de los estatutos corporativos, la decisión adoptada en Winthrop v. Lechmere no era ni mucho menos un audaz coup de main, como dice Goebel ${ }^{76}$, aunque la colonia de Connecticut lo contemplara como tal, haciendo grandes esfuerzos para intentar revocar la decisión y reparar el daño que, a juicio de la colonia, había causado el Privy Council. No dejaba de haber una cierta ironía en la situación, pues desde los primeros días de la colonización de Nueva Inglaterra, las Charters se habían considerado por los colonos, en sus relaciones con sus propios gobiernos, como una especie de constitución, y ahora el supremo órgano jurisdiccional sujetaba a su propia autoridad legislativa a la letra de aquellos instrumentos.

Este temprano ejemplo de anulación judicial de la legislación, de resultas de considerarse la misma en conflicto con un higher law, muestra según McGovney muchos de los defectos que iban a aparecer frecuentemente en casos posteriores. El primero de ellos, el que el caso era por entero un litigio entre partes privadsas, lo que suponía que el gobierno de Connecticut no iba a ser oído en relación a una ley que se consideraba de vital importancia para la economía de la colonia. La disfuncionalidad de esta circunstancia se iba a acentuar en el caso sub judice, dadas las pobres argumentaciones de los abogados que actuaron en nombre de Lechmere, muy poco conocedores de los hechos económicos subyacentes a la aprobación de esta legislación, no obstante tratarse de dos relevantes juristas, como muestra el hecho de que uno de ellos, John Willes, llegara a ser después ChiefJustice of Common Bench. El resultado, argumenta el propio autor ${ }^{77}$, podía haber sido diferente si se hubiera mostrado ante el Privy Council que la Ley en cuestión de 1699 no había sido sino la transformación en Derecho positivo de una costumbre que había prevalecido desde el inicio mismo de la colonia, de dividir los bienes raíces de los intestados entre todos los hijos, y que declarar que la regla de la primogenitura había estado en vigor desde los comienzos de la vida de Connecticut lo único que conseguiría es introducir un elemento de confusión sobre los títulos de muchas personas sobre las tierras de la colonia. Dicho de otro modo, el resultado final hubiera sido posiblemente diferente si se hubiera mostrado adecuadamente que la regla fijada por la Ley de 1699 era mucho más conveniente para el desarrollo económico de la colonia, de lo que lo era la norma seguida por el common law.

Las actas del caso Winthrop v. Lechmere no llegaron a imprimirse, y aunque existen pruebas de que la decisión fue muy bien conocida no sólo en Connecticut, sino también en Massachusetts y Virginia, puede que no llegara a ser universalmente conocida. Benjamin Whitaker, Chief Justice de Carolina del Sur entre 1739 y 1750,no parecía conocerla en 1742. Él sabía que la Legislatura de Carolina del Sur se hallaba sujeta a limitaciones constitucionales, pues las normas aprobadas por la Legislatura no podían contrariar las leyes 
de Inglaterra, pero dudaba acerca de si los tribunales podían hacer efectiva esa limitación, declarando la nulidad de un estatuto que transgrediera tales límites ${ }^{78}$.

La apropiación de la facultad de pronunciarse, al hilo del ejercicio de sus funciones jurisdiccionales, acerca de la validez de un estatuto colonial no dejaba de ser, en 1727, novedosa por parte del Privy Council, no obstante la existencia de un cierto control judicial de la conformidad de la legislación colonial con las Charters, al que ya nos hemos referido, pero que en cualquier caso era algo diferente. Sin embargo, de ahí en adelante, y por lo menos hasta mediados del siglo XIX, el Privy Council nunca puso en duda tal facultad, de la que, tras la independencia de Norteamérica, también hizo uso en relación a la legislación proveniente de la India, del Canadá y de Australia.

\section{El caso Philips v. Savage (1737).}

I. El siguiente gran caso que encontramos en relación con el tema que nos ocupa es el caso Philips v. Savage, del año 1737. El caso surgió a raíz de una apelación frente a una decisión de un tribunal de Massachusetts. Los hechos del caso pueden resumirse como sigue. En 1729, el bostoniano Henry Philips murió intestado, sobreviviéndole su madre, su hermano Gillam y dos hermanas (una de ellas la mujer de Habijah Savage, y la otra casada con Arthur Savage), además de los hijos de otra hermana ya fallecida. En mayo de 1733, la Probate Court, esto es, el tribunal de legalización de testamentos, al que ya nos hemos referido, del condado de Suffolk (Massachusetts) ordenó que tanto los bienes raíces como los personales del fallecido fueran divididos en cinco partes iguales, distribuyéndose entre esos parientes próximos, de conformidad con lo dispuesto por una ley de Massachusetts de 1692.

En octubre de 1733, Gillam Philips apeló frente a la anterior decisión judicial ante el Gobernadsor y el Council, que era el tribunal de última instancia de Massachusetts, al considerarse como el único heredero en Derecho de su difunto hermano, en cuanto que, a su juicio, "no act of that Province could vary the common law of the realm, or change or alter the course of descents", por lo que la le de Massachusetts y la decisión adoptada por la Probate Court de Suffolk en aplicación de la misma eran "repugnant or contrary to the

\footnotetext{
$78 \quad$ No otra cosa parece inferirse del memorial que el Chief Justice Whitaker dirigia al Gobernador de Carolina del Sur el 16 de septiembre de 1742, en el que se podia leer lo que sigue: ".... altho the Judges of the Courts of Common Law in Great Britain are the proper Expositors of Acts of Parliament, yet in the Plantations in America which are dependent Governments and are only impowered to make Laws, under certain Conditions, Limitations and Restrictions, the Judges in America are bound to observe the Laws that are passed by the General Assembly, till they are repealed by the King. For though such Laws may sometimes be made contrary to his Majesty's Royal Prerogative; or his Instructions to his Governors, or may be repugnant to the Laws of England, yet it is conceived such Laws are not Ipso facto void, in themselves, but only voidable by his Majesty's disallowance or repeal, who 'tis humbly apprehended has reserved to himself the Sole power of Judging of Such Contrariety, or repugnancy...". Apud Dudley Odell McGOVNEY, "The British Origin...", op. cit., pp. 38-39.
} 
laws of the realm of England, and consequently ipso facto void"79. En el siguiente mes de noviembre, el Gobernador y el Council rechazaron la apelación, confirmando la decisión judicial impugnada por Gillam. Éste solicitó a su vez la autorización para apelar ante el Privy Council, que, inicialmente, le fue denegada, aunque con posterioridad, en febrero de 1734, le fue finalmente concedida. Como fácilmente se puede apreciar, la similitud de este caso con Winthrop v. Lechmere es enorme.

El abogado de Gillam Philips, el distinguido Sir Dudley Rider, con posterioridad Lord Chief Justice de Inglaterra, antecesor en el cargo por cierto del gran Lord Mansfield, mencionó en su apoyo el precedente sentado por el caso Winthrop v. Lechmere, pero el muy inteligente alegato del abogado de una de sus dos hermanas (Faith Savage) iba a la postre a ser determinante del fallo dictado por el Privy Council. En síntesis, esa argumentación giró en torno a estas tres consideraciones: la primera de ellas, que vincular a las legislaturas coloniales a hacer leyes "perfectly agreeable to the law of England" convertiría las facultades de esos órganos en algo por entero inútil; la segunda, que el estatuto en cuestión se había adaptado a las condiciones económicas de la colonia, pues si el hijo mayor o, como aquí sucedía, el hermano mayor, se apropiaba de la totalidad de la tierra, "los niños pequeños quedaban condenados a andar errantes por la vida para poder comer". "Descendents ---se afirmaba--- must be governed by the circumstances of every country". La tercera reflexión era que la inconveniencia pública general ("public general inconvenience") no era en modo alguno un argumento indigno de consideración en Derecho, y declarar la nulidad de la ley después de estar aplicándose durante cuarenta y cinco años en miles de casos produciría múltiples confusiones" ${ }^{80}$.

El 15 de febrero de 1738, el Privy Council decidía el caso a través de una Order, por la que confirmaba las sentencias de los tribunales de Massachusetts. En la decisión se ignoraba el precedente sentado en Winthrop v. Lechmere. Ello no debía entenderse en el sentido de que el Privy Council considerase que no podía ejercer una función de revisión judicial de la constitucionalidad de una ley colonial, sino más bien en el de un implícito reconocimiento de lo erróneo de su anterior decisión. Es más que probable que la diferencia del fallo se debiese a los argumentos expuestos por la parte demandada, de los que acabamos de hacernos eco. Se ha apuntado también como base en la que explicar la diferencia, al hecho de que la ley de Massachusetts había sido reafirmada por una Order in Council de 1695, al margen ya de que diversas normas legales aclaratorias de la misma, de los ańos 1710, 1715 y 1719, no habían sido rechazadas por la Corona, y otro texto legal, aprobado en 1731, había recibido la confirmación real.

\footnotetext{
79 Apud Arthur Meier SCHLESINGER, "Colonial Appeals..." (II), op. cit., p. 442.

80 Dudley Odell McGOVNEY, "The British Origin...", op. cit., pp. 20-21.
} 
II. La decisión del caso Philips v. Savage impulsó al pueblo de Connecticut en sus esfuerzos para lograr el restablecimiento de la ley sobre los intestados. El hecho de que Winthrop v. Lechmere se tratase de un caso particular en el que el Privy Council no tuvo oportunidad de oír la opinión de la colonia y lo inadecuado de la defensa de Thomas Lechmere aún hacían más necesario el replanteamiento de la cuestión ante el Privy Council.

La oportunidad no iba a tardar muchos años en presentarse. Iba a tener lugar en 1745 en el caso Clark v. Tousey. En 1737, Samuel Clark, de Milford, apeló al King in Council para recuperar ciertas tierras en Connecticut, tierras que demandaba como heredero legal de conformidad con las leyes inglesas sobre la descendencia, pero que, de acuerdo con la normativa jurídica de Connecticut, le habían sido atribuidas a él conjuntamente con Thomas Tousey, de Newton, y Hannah, su esposa, así como de otros cuatro demandados. Una primera Order in Council de mayo de 1738, admitiendo la apelación, no le llegó a Clark dentro del plazo legalmente establecido para apelar, pero como el litigio judicial continuó ante los tribunales de Connecticut, tras ver derrotadas sus pretensiones ante ellos, le fue concedida una segunda petición de apelación en mayo de 1742. Ese mismo mes, Tousey se presentó ante la Asamblea legislativa de Connecticut, declarando que estaba obligado a ir a Inglaterra para defender su causa. A la vista del interés general que presentaba el litigio para toda la ciudadanía, la Asamblea aprobó conceder una suma de 500 libras en apoyo de Tousey.

El reconocimiento de lo injusto que sería aplicar el Derecho consuetudinario de un país (Inglaterra) en detrimento de una zona concreta del mismo (Connecticut), en la que la vida económica agraria había generado costumbres bien distintas, al margen ya del precedente de Philips $v$. Savage y de las presiones de la colonia, alegando razones de pura conveniencia social y económica, lograron finalmente el objetivo perseguido: la revocación por el Privy Council de su anterior decisión en Winthrop v. Lechmere. La apelación de Clark fue desestimada a través de una Order in Council de 18 de julio de 1745, lo que conllevaba el restablecimiento de la validez de la Ley de Connecticut de 1699.

\section{El caso Camm v. Hansford and Moss (Parson's Cause) (1766).}

Un nuevo y relevante caso en el que se iba a plantear la validez de un estatuto colonial iba a ser el caso Camm v. Hansford and Moss, mucho más conocido popularmente como la Parson's Cause. En él se iba a cuestionar la validez constitucional de la virginiana Two Penny Act de 1658. Se ha dado una gran significación a este caso, por cuanto muestra que en la segunda mitad del siglo XVIII la facultad del Privy Council de pronunciarse sobre la validez de la legislación colonial, con ocasión de su ejercicio de la función jurisdiccional, era perfectamente comprendida en América, comenzando a visualizarse que también los tribunales coloniales podían llevar a cabo pronunciamientos semejantes. Además, según 
McGovney ${ }^{81}$, la historia de la Two Penny Act ilustra no sólo acerca de la facultad de anulación judicial, sino también sobre otros mecanismos existentes en el sistema colonial británico para el control de la legislación colonial. De ahí que convenga recordar con algún detalle el complejo itinerario seguido por este caso.

Virginia, que contaba con un gobierno establecido desde hacía siglo y medio, tenía a mediados del siglo XVIII una próspera situación social y económico. Dos rasgos podían destacarse en la colonia en relación con el caso que ahora interesa. El primero era que la moneda colonial no adoptaba como patrón tan sólo el oro o la plata, sino también el tabaco. El segundo era que el clero que se iba a ver implicado en la controversia era el clero de la Iglesia Anglicana, una Iglesia reconocida y mantenida con impuestos públicos recaudados de entre todos los habitantes, pues en Virginia la separación entre la Iglesia y el Estado no se produciría hasta después de la Independencia.

En 1696, el salario anual de cada ministro de la Iglesia Anglicana se había fijado por medio de un estatuto en el equivalente a 16.000 libras de tabaco. Una ley de 1748, en apoyo del clero, confirmada por el Privy Council, modificó la anterior previsión, adicionándole un 4 por 100 por la reducción que el sueldo hubiere podido experimentar. Entre 1755 y 1763 , la situación iba a experimentar un cambio radical. Virginia combatió con las demás colonias junto a la madre patria en la llamada "French and Indian War". Para hacer frente a la guerra se emitieron cartas de crédito y pagarés del tesoro, y este "papel moneda" fue declarado de curso legal. La guerra condujo a la depresión económica, siendo este el escenario en que se iba a situar la Two Penny Act, cuyo propósito era devaluar el tabaco como un patrón de valor. La Two Penny Act de 1758 tuvo su precursora en la Two Penny Act de 1755, que estableció que las deudas del tabaco podían pagarse, a opción del deudor, en moneda de curso legal, a un precio de dos peniques por cada libra de tabaco que se debiera. A la ley se le daba una vigencia temporal mínima, de tan sólo diez meses. El clero protestó, poniendo de relieve que esta norma les perjudicaba mucho más a ellos que a los acreedores de tabaco. En vano intercedieron ante el gobierno para que la vetara. En una carta suscrita por ocho clérigos, la ley era tildada de "glaringly inconsistent with the natural equity, the rights of the clergy, the common liberty of the subject" 82 .

La Two Penny Act de 1758, como la que le había antecedido tres años antes, permitía que la deuda de una libra de tabaco fuera liberada mediante el pago de dos peniques en moneda de curso legal. La ley se aplicaba a la casi totalidad de los deudores de tabaco ("any person or persons, from whom any tobacco is due by judgment, for rent, by bond, or upon any contract, or for public, county, or parish levies; or for any secretary's, clerks, sheriffs, surveyors, or other officers fees”). El clero entendió que el estatuto les venía a sustraer unas dos terceras partes de su salario al ańo, al margen ya de que consideraran que tales salarios

\begin{tabular}{ll}
\hline 81 & Ibidem, p. 22. \\
82 & Ibidem, p. 24.
\end{tabular}


se habían devengado antes de que la ley se aprobara (la ley se había promulgado el 12 de octubre, pero el salario anual no se debía legalmente hasta unos meses después). Tras la aprobación del texto legal por las dos Cámaras de la Legislatura virginiana, una diputación del clero acudió al Gobernador Fauquier, exponiéndole que la ley era contraria a la razón y a la justicia común ("to reason and common justice"), recordándole "amablemente" que su firma contrariaría los que habían sido sus principios de gobierno. El Gobernador declinó hacer uso de su derecho de veto, ante lo que una convención del clero convino en enviar al Reverendo John Camm a Inglaterra a fin de que requiriera al Privy Council el rechazo del estatuto, petición a la que se unieron algunos comerciantes de Londres que mantenían negocios con Virginia.

La Board of Trade recurrió al Obispo de Londres, a fin de conocer su opinión. El Obispo manifestó que el curso de esta legislación de Virginia mostraba un propósito de socavar a la Iglesia oficialmente reconocida, a disminuir sus prerrogativas y la influencia de la Corona, y que el Gobernador y el Consejo parecían actuar de mutuo acuerdo con el pueblo. Así las cosas, la Board of Trade puso de relieve ante el Privy Council que la ley era injusta, y que se había promulgado con violación del art. XVI de las Instrucciones de la Corona al Gobernador de Virginia, debiendo por ello mismo ser rechazada.

El 10 de agosto de 1759 el Privy Council rechazaba el estatuto de Virginia, de lo que no se tuvo noticia por el Gobernador de Virginia hasta el 27 de junio de 1760. Entre tanto, la vigencia de la ley de 1758, fijada por un período brevísimo, como ya se dijo, expiró el 12 de octubre de 1759, pero los impuestos recaudados para el pago de los salarios de los ministros de la Iglesia se había hecho de acuerdo con sus términos, considerándose legales a todos los efectos, pues la aplicación de la ley se consideraba plenamente válida hasta el momento en que se tuviera noticia de su rechazo por el Privy Council. Dicho de otro modo, el rechazo del texto legal no operaba con efectos retroactivos. Pero el clero no estaba dispuesto a dejar escapar ni una sola de sus posibilidades para lograr la anulación radical del texto estatutario, esto es, su declaración como void ab initio. Y para ello aún le restaba un último instrumento: el recurso a los tribunales, a fin de que éstos consideraran nula la ley desde el mismo momento de su promulgación, con base en la carencia constitucional por parte de la Legislatura virginiana de una facultad para promulgarla.

El clero sostenía que el estatuto era inconstitucional por dos razones: $1^{\text {a) }}$ Un acto legislativo contrario a la justicia natural es nulo. $2^{\text {a) }}$ La ley había sido firmada por el Gobernador con violación del artículo XVI de sus Instrucciones, lo que planteaba a su vez la cuestión de si las instrucciones de la Corona a un Gobernador real eran limitaciones constitucionales sobre la Legislatura, órgano del que él mismo era una parte esencial. El mencionado artículo XVI le prohibía asentir a toda ley que derogara cualquier Derecho antiguo, a menos que tal ley contuviera una cláusula suspendiendo la derogación hasta que "his Majesty's pleasure be known". Y de lo que no cabe duda es de que la Two Penny Act, 
parcialmente al menos, derogaba la anteriormente mencionada ley de 1748, no conteniendo ninguna cláusula suspensiva, por cuanto sus términos eran de aplicación inmediata.

En este marco contextual, cinco ministros de la Iglesia Anglicana presentaron separadamente otras tantas demandas en distintos tribunales virginianos, con la idea, si ello era necesario, de llegar a un pronunciamiento del Privy Council. Cada uno de ellos demandaba al recaudador de su parroquia con vistas a recuperar el precio de mercado del tabaco asignado como salario, precio que se hallaba en torno a los seis peniques la libra de tabaco, esto es, el triple de lo que había fijado la ley. McGovney se ha hecho eco de la imprecisión existente acerca del devenir de alguna de esas demandas ${ }^{83}$. Con todo, lo que sí está claro es que la demanda formalizada por el Reverendo James Maury ante la Hannover County Court culminó con una decisión judicial de 5 de noviembre de 1763 por la que los jueces "adjudged the two penny act to be no law", desconociéndose los fundamentos del fallo, aunque lo más probable es que una tal decisión respondiera a la consideración de que el Gobernador había firmado la ley contraviniendo sus Instrucciones. En dos de las demandas parece que la ley se consideró válida. En una cuarta demanda la vista se aplazó hasta tanto la General Court se pronunciara frente a la demanda formalizada por el Reverendo John Camm.

La General Court virginiana era el Tribunal superior de justicia de Virginia, hallándose integrada por elo Gobernador y su Consejo, con un total de doce miembros. En el caso del Reverendo Camm, la Corte consideró válida la ley por una apretada votación de 5 votos frente a 4, dado que el Gobernador, como era costumbre, no votó y dos de sus miembros no participaron por tener interés en la cuestión planteada. Aunque sólo cuatro de los miembros de la General Court consideraron el estatuto inválido, por carecer la Legislatura de competencia para promulgarlo, lo cierto es que nadie del mismo órgano dudó de que la Corte pudiera pronunciarse en tal sentido.

Frente a la decisión anterior, dictada en el caso que se identificó como Camm v. Hansford and Moss, el Reverendo John Camm manifestó su deseo de apelar al Privy Council. No había ninguna duda por parte del clero anglicano de Virginia de la facultad del Privy Council de declarar la nulidad de una ley desde el mismo momento de su promulgación (void ab initio), si es que tal órgano compartía las tachas de inconstitucionalidad aducidas por el clero. Los abogados que actuaron ante el Privy Council en defensa de la posición del demandante, el Reverendo Camm, mencionaron el precedente de Winthrop v. Lechmere del año 1727, recordando que en esa apelación el órgano judicial había declarado la nulidad de dos leyes de la Asamblea de Connecticut. Por parte de los demandados intervino con enorme acierto Charles Yorke, hijo del Lord Chancellor Hardwicke, para quien la argumentación del demandante suscitaba tan sólo una cuestión puramente jurídica, sin que hubiera habido prueba suficiente respecto de los hechos como para demostrar que el tabaco era merecedor

$\overline{83}$ Cfr. al efecto, Dudley Odell McGOVNEY, "The British Origin...", op. cit., pp. 27-28. 
de una cantidad superior a los dos peniques por libra, no existiendo tampoco prueba en el sumario de la causa de que la ley en cuestión causara dificultades, al margen ya de que la ley era general, aplicándose a todos los deudores de tabaco, y además, "no debía de presumirse que la Legislatura de Virginia hubiese aprobado la ley si no se hallara convencida de su necesidad".

Particular interés iba a presentar la argumentación que en nombre de los demandados iba a hacer Charles Yorke acerca de la cuestión constitucional planteada ante el Privy Council. A su entender, el encargo que se había otorgado al Gobernador de Virginia le daba "con el consentimiento" del Consejo y de la Asamblea, "pleno poder.... para hacer leyes.... para la paz pública, el bienestar y el buen gobierno" de la colonia, "no contradictorias, sino tan cercanas como puedan estar conformes con las leyes y estatutos de este reino de Gran Bretaña”, siempre que todas las leyes promulgadas se envíen dentro del plazo de tres meses para su "aprobación o rechazo", y en el caso de un estatuto rechazado, el rechazo había de significar para el Gobernador que la ley había de cesar en su aplicación desde entonces, convirtiéndose en completamente nula y quedando sin ningún efecto. Y en cuanto a la ley en cuestión, que se encaminaba a suspender la vigencia de la Ley de 1748, texto legal éste que había recibido la aprobación real, había que entender que una competencia dada por la Corona para hacer leyes implicaba una competencia para suspender o incluso abrogar leyes anteriores, que se consideraran inconvenientes o perjudiciales, como lo era la de 1748, pues de otro modo un país situado a 3000 millas de distancia podría hallarse sujeto a grandes calamidades antes de que pudiera obtenerse ayuda.

El Privy Council pronunció su decisión el 3 de diciembre de 1766, orientándola en el sentido de confirmar la sentencia de la General Court de Williamsburg, en la colonia de Virginia, dictada a su vez el 10 de abril de 1764, desestimando como es obvio la apelación formulada contra ella. Aunque a primera vista pareciera tratarse de una decisión sobre el fondo del asunto, hay alguna razón para dudar de ello, pues como señala la doctrina ${ }^{84}$, Yorke adujo que el Reverendo Camm había entablado su pleito por medio de una acción errónea, por cuanto había formalizado una acción de abuso en vez de una acción de deuda; esta objeción, desde un punto de vista técnico, procesal, parecía tener sólidos fundamentos. Además, existe copia de una nota garabateada por el mismo Yorke, en su propio informe, en la que se indica que la apelación se desestimó por razones técnicas, esto es, formales. El clero de Virginia también pareció comprenderlo así, al quejarse de que el Privy Council se había valido de esta cuestión técnica para soslayar una decisión sobre el fondo, por temor a añadir con la misma un mayor descontento al que ya se había manifestado en las colonias americanas ese mismo año por la generalizada resistencia opuesta frente a la Stamp Act. Ahora bien, que Charles Yorke sostuviera en este litigio la validez de la Two Penny Act en modo alguno había de entenderse en el sentido de que pensara que el Privy Council carecía de la facultad de considerar tal ley inválida. Es significativo al respecto recordar que seis años

$\overline{84}$ Dudley Odell McGOVNEY, "The British Origin...", op. cit., p. 31. 
antes, en 1760, como Solicitor General, había formulado una opinión oficial interpretando que tal facultad era una función normal del Privy Council. Más aún, su padre aún vivía y su hijo no podía ignorar los puntos de vista de su padre expuestos ante el Privy Council, y aceptados por éste como ya se vio, en el caso Winthrop $v$. Lechmere.

Unos pocos años después, uno de los tribunales de "Westminster Hall”, el King's Bench, consideraría nula una decisión legislativa del King in Council pronunciada por la Corona conforme a un supuesto poder de legislar para la colonia de Granada. A su vez, en mayo de 1767, el Privy Council se refería a su vieja decisión dictada en el caso Winthrop v. Lechmere, en una comunicación dirigida a la House of Lords. Por lo demás, McGovney ha insistido en la existencia de una clara y directa evidencia de que esta doctrina británica fue plenamente aprovechada por el pensamiento colonial ${ }^{85}$. Y al efecto recuerda cómo William Samuel Johnson, agente de Connecticut en Inglaterra, informaba al Gobernador de esa colonia del muy interesante debate que había mantenido en 1768 con Lord Hillsborough, debate que revela que un colono de Connecticut comprendía perfectamente la distinción entre el rechazo por el ejecutivo de un estatuto colonial y la decisión judicial de que el estatuto era nulo. El dato es significativo si se advierte que Johnson fue uno de los delegados por Connecticut a la Convención de Filadelfia de 1787, pues revela que este delegado se hallaba plenamente familiarizado con la judicial review antes de que llegara a la Convención Constituyente.

En resumen, la etapa colonial, incluso bastante antes de James Otis, nos ofrece ejemplos de aplicación de la doctrina de la judicial review y, sobre todo, nos muestra que tal doctrina era bien conocida y admitida en amplios sectores del mundo jurídico colonial.

\section{REFERENCIAS}

BAILYN, Bernard. The Ideological Origins of the American Revolution, Cambridge (Mass.), The Belknap Press of Harvard University Press, 13th printing, 1976, pp. 193 y ss.

BERGER, Raoul. Congress v. the Supreme Court, Cambridge (Mass.), Harvard University Press, 2nd edition, 1974 (first published in 1969).

BETH, Loren P. "The Judicial Committee of the Privy Council and the Development of Judicial Review", en The American Journal of Comparative Law (Am. J. Comp. L.), Vol. 24, 1976, pp. 22 y ss.

BURGER, Warren E. “The Doctrine of Judicial Review. Mr. Marshall, Mr. Jefferson, and Mr. Marbury”, en Current Legal Problems (The Faculty of Laws. University College London), Vol. 25, 1972, pp. 1 y ss.

BURNS, Edward M. "Madison's Theory of Judicial Review”, en Kentucky Law Journal (Ky. L. J.), Vol. XXIV, 1935-1936, pp. 412 y ss. 
CONWAY Daniel (ED). The Writings of Thomas Paine, New York, Burt Franklin, reprinted, 1969, Vol. I (1774-1779).

CORWIN, Edward S. "The <Higher Law>Background of American Constitutional Law" (II), en Harvard Law Review (Harv. L. Rev.), Vol. XLII, 1928-1929, pp. 365 y ss.

CORWIN, Edward S. “The Establishment of Judicial Review” (I), en Michigan Law Review (Mich. L. Rev.), Vol. IX, 1910-1911, pp. 102 y ss.

COX, Archibald. "The Independence of the Judiciary. History and Purposes", en University of Dayton Law Review (U. Dayton L. Rev.), Vol. 21, 1995-1996, pp. 565 y ss.

CURRIE, David P. "The Constitution in the Supreme Court. The Powers of the Federal Courts, 1801-1835”, en The University of Chicago Press (U. Chi. L. Rev.), Vol. 49, 1982 , pp. 646 y ss.

DIONISOPOULOS, P. Allan; PETERSON, Paul. "Rediscovering the American Origins of Judicial Review: A Rebuttal to the Views Stated by Currie and Other Scholars", en John Marshall Law Review (J. Marshall L. Rev.), Vol. 18, 1984-1985, pp. 49 y ss.

ELLIOTT, Mark. The Constitutional Foundations of Judicial Review, Oxford/Portland (Oregon), Hart Publishing, 2001.

FERNÁNDEZ SEGADO, Francisco. "James Otis y el Writs of Assistance Case (1761)", en Anuario Iberoamericano de Justicia Constitucional (AIbJC), núm. 18, 2014, pp. 155 y ss.

FOWLER, Robert Ludlow. "The Origin of the Supreme Judicial Power in the Federal Constitution”, en American Law Review (Am. L. Rev.), Vol. 29, 1895, pp. 711 y ss.

FRANK, John P. "Historical Bases of the Federal Judicial System”, en Indiana Law Journal (Ind. L. J.), Vol. 23, 1947-1948, pp. 236 y ss.

FRIEDRICH, Carl J.; McClOSKEY, Robert G. (Ed). From the Declaration of Independence to the Constitution (The Roots of American Constitutionalism), Indianapolis (Indiana)/New York, The Bobbs-Merrill Company Inc., 1954, pp. 3 y ss.

GOEBEL, Jr., Julius. Antecedents and Beginnings to 1801 (History of the Supreme Court of the United States. Vol. 1), New York/London, The Oliver Wendell Holmes Devise, Macmillan Publishing Co., Inc./Collier Macmillan Publishers, 2nd printing, 1974, pp. 60-83.

GOEBEL, Jr., Julius. "Ex Parte Clio", (Books Review), en Columbia Law Review (Colum. L. Rev.), Vol. LIV, 1954, pp. 450 y ss.

GRABER,Mark A.; PERHAC Michael (editors). Marbury versus Madison. Documents and Commentary, Washington, CQ Press (A Division of Congressional Quarterly Inc.), 2002.

GREY, Thomas C. "Origins of the Unwritten Constitution: Fundamental Law in American Revolutionary Thought”, en Stanford Law Review (Stan. L. Rev.), Vol. 30, 19771978, pp. 843 y ss.

HAINES, Charles Grove. The American Doctrine of Judicial Supremacy, Berkeley, California, University of California, 2nd edition, 1932, p. 45.

HAMBURGER,Philip. "Law and Judicial Duty", en George Washington Law Review (Geo. Wash. L. Rev.), Vol. 72, 2003-2004, pp. 1 y ss. 
HARRINGTON, Matthew P. "Judicial Review Before John Marshall”, en George Washington Law Review (Geo. Wash. L. Rev.), Vol. 72, 2003-2004, pp. 51 y ss.

KRAMER, Larry D. "We the Court" (The Supreme Court 2000 Term. Foreword), en Harvard Law Review (Harv. L. Rev.), Vol. 115, 2001-2002, pp. 5 y ss.

McGOVNEY, Dudley Odell. “The British Privy Council's Power to Restrain the Legislatures of Colonial America: Power to Disallow Statutes: Power to Veto”, en University of Pennsylvania Law Review (U. Pa. L. Rev.), Vol. 94, 1945-1946, pp. 59 y ss.

McGOVNEY, Dudley Odell. "The British Origin of Judicial Review of Legislation”, en University of Pennsylvania Law Review (U. Pa. L. Rev.), Vol. 93, 1944-1945, pp. 1 y ss.

MEIGS, William M. “The American Doctrine of Judicial Power, and Its Early Origin”, en American Law Review (Am. L. Rev.), Vol. 47, 1913, pp. 683 y ss.

NELSON, William E. "Marbury v. Madison, Democracy, and the Rule of Law", en Tennessee Law Review (Tenn. L. Rev.), Vol. 71, 2003-2004, pp. 217 y ss.

PINCUS, Steve.1688. La primera revolución moderna, Barcelona, Acantilado, 2013.

PLUCKNETT, Theodore F. T. "Bonham's Case and Judicial Review”, en Harvard Law Review (Harv. L. Rev.), Vol. XL, 1926-1927, pp. 30 y ss.

\section{Francisco Fernández Segado}

Universidad Complutense de Madrid

fdezsegado@der.ucm.es 